\title{
الاستثمار الخاص ودوره في عملية الإصلاح الاقتصادي في العراق
}

\author{
د.احمد عمر الراوي \\ مركز المستتصرية للاراسات العربية والداولية الدية
}

الاقدهمة بعدة

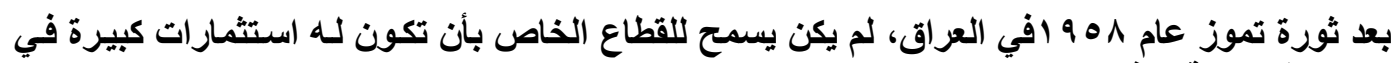

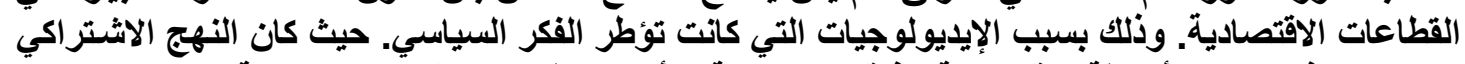

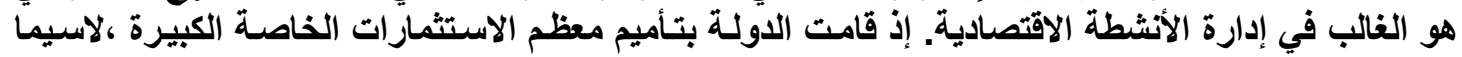

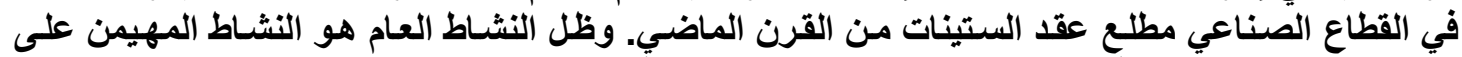

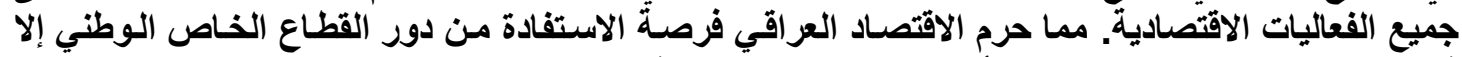

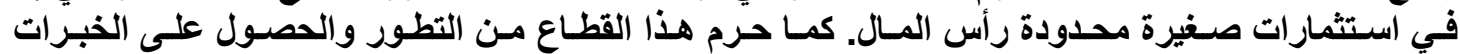
التكنولوجية، نتيجة عدم السماح للاستثمار الأجنبي بالعمل داخدم التل العراق.

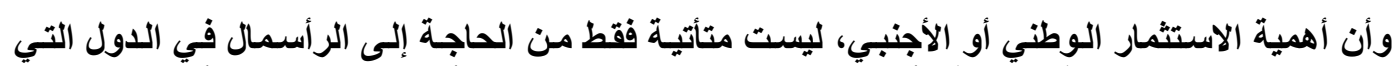

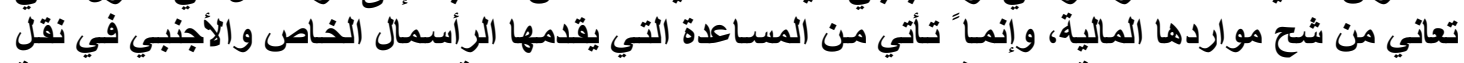

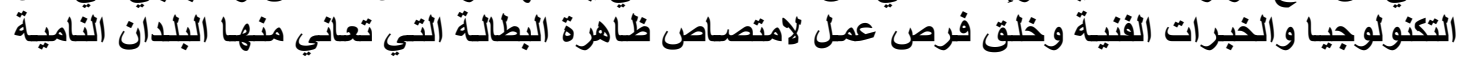

ومنها البلان العربية والخبرات

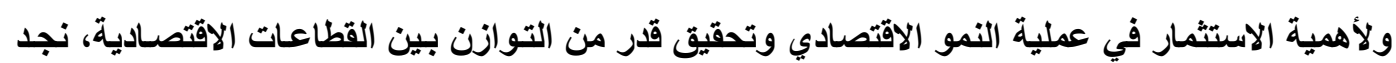

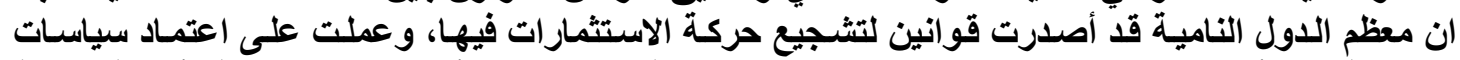

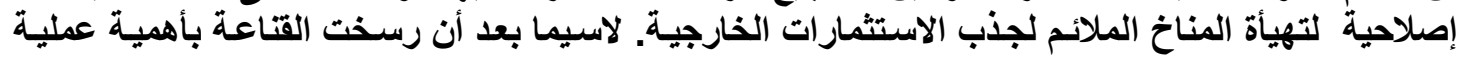

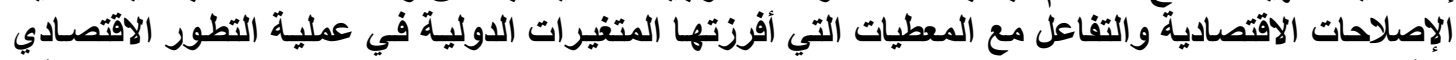

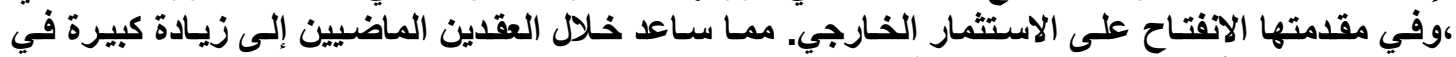

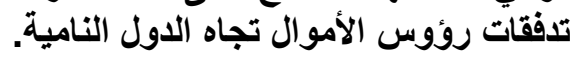

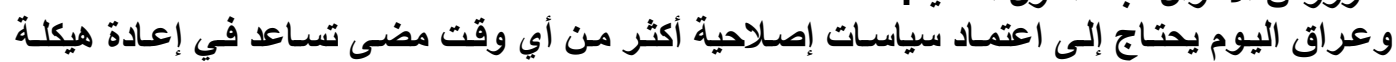

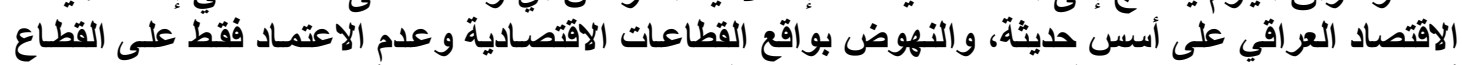

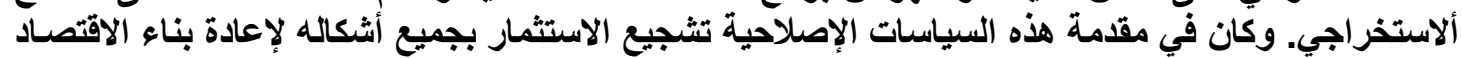

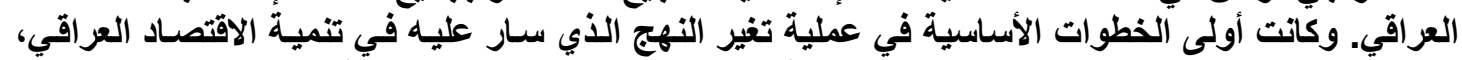

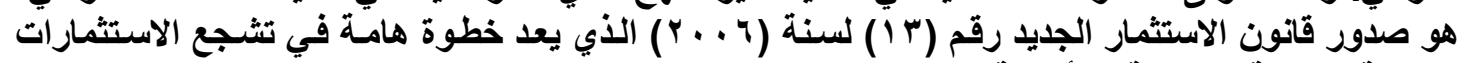

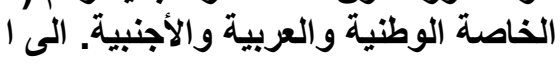

فرضية البحث

يستند البحث إلى فرضية مفادها إن للنشاط الاستثماري الخاص دور هام في عملية الإصلاح الاقتصسادي بالعراق.

\section{هدف البمث}

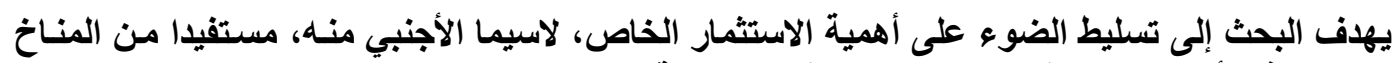

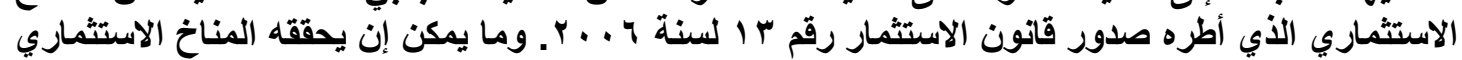

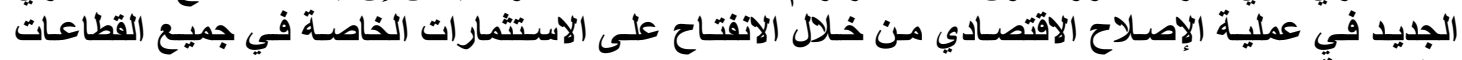

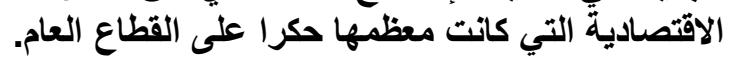




\section{المبحث الأول/ واتع الاقتصاد العراقي وأهـية الإصلاح}

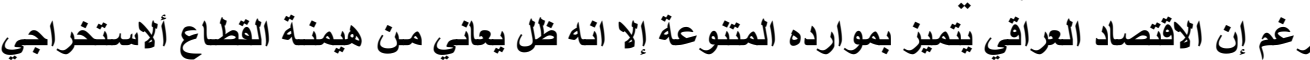

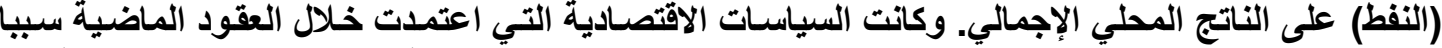

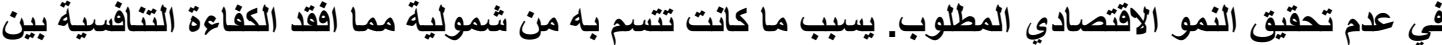

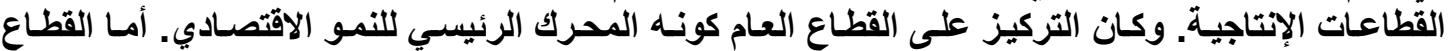

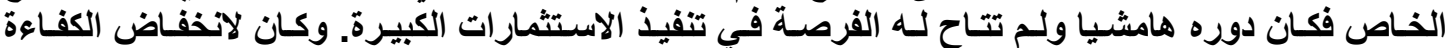

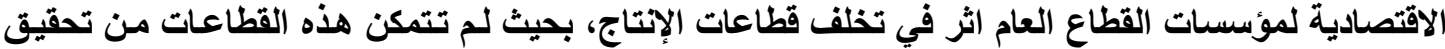

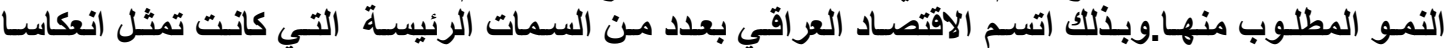

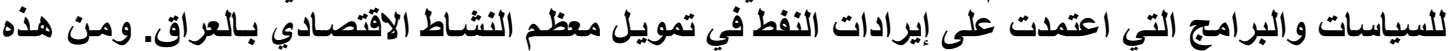

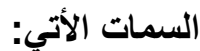
ا - هيمنة القطاع النفطي على الاقتصاد:

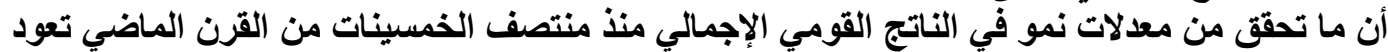

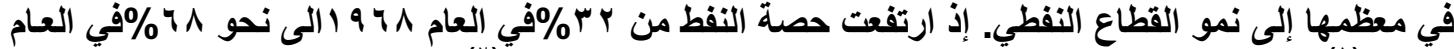

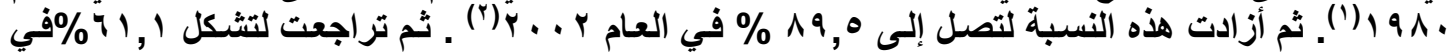

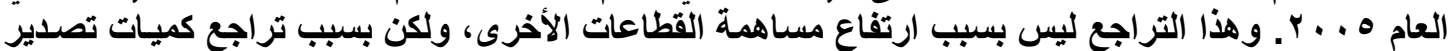

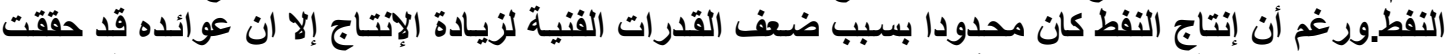

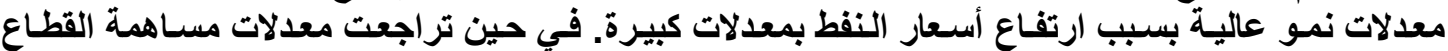

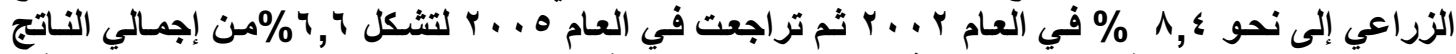

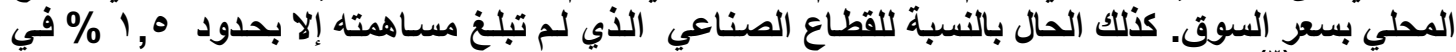

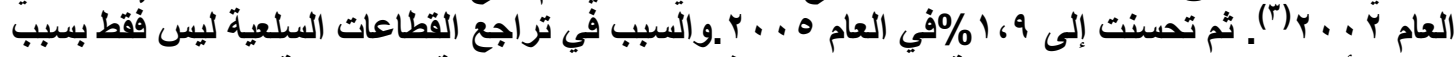

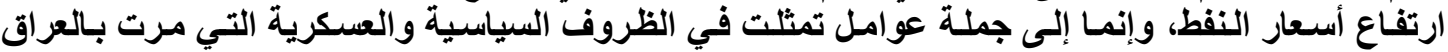

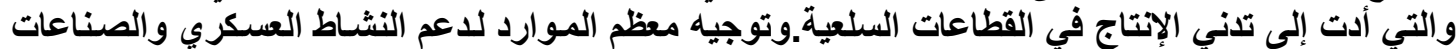

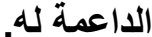

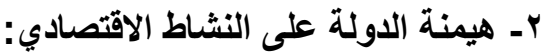

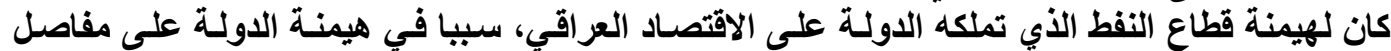

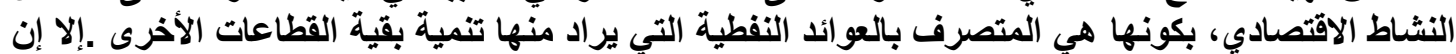

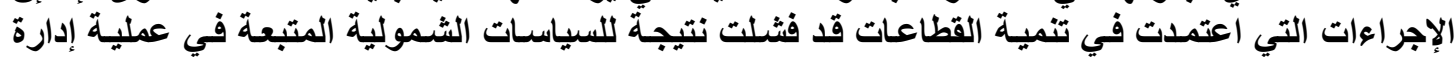

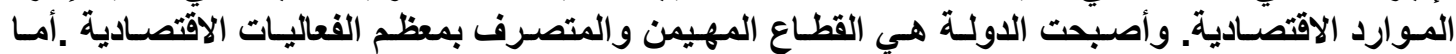

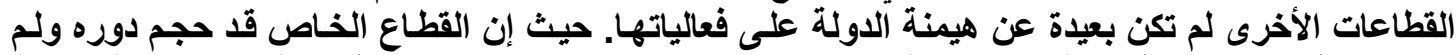

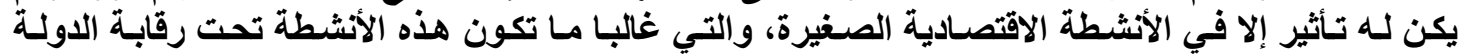

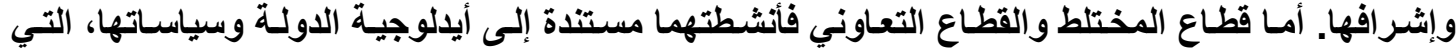

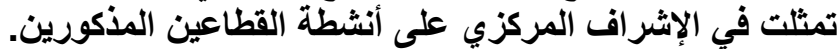

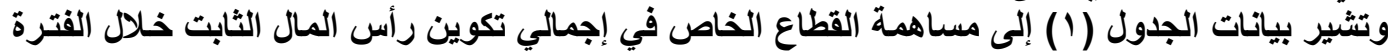

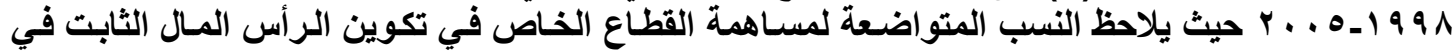

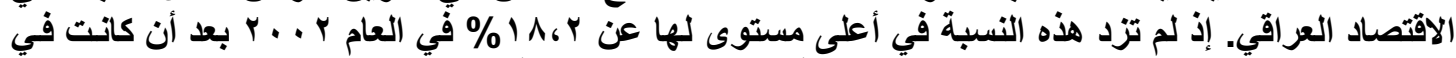

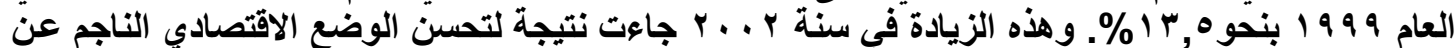

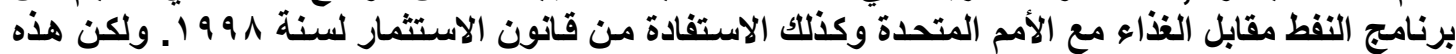

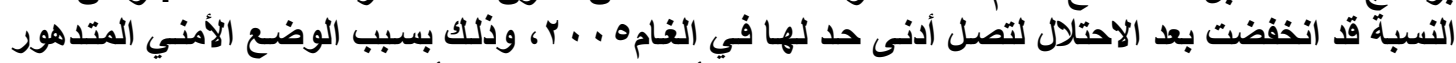

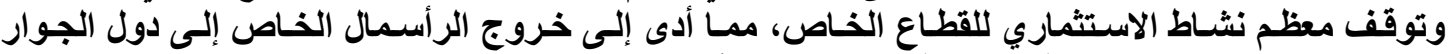

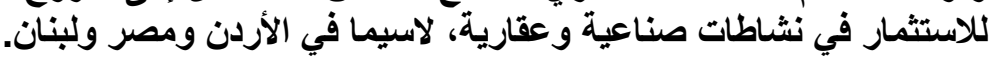

\begin{tabular}{|c|c|c|c|c|}
\hline نسبة الخاص/ المجموع \% & المجموع & القطاع الخاص & القطاع العام & السنة \\
\hline
\end{tabular}




\begin{tabular}{|c|c|c|c|c|}
\hline 17,1 & $\{1 Y, 70,1$ & צ & r & 1991 \\
\hline $1 \%, 0$ & $V 0 \leq \varepsilon q Y, 7$ & $1 . r Y \Lambda . \cdot$ & YOYY.O & 1999 \\
\hline $1 \cdot, r$ & I\&7०YOY,V & $10 \cdot \mu \mu V, 7$ & $14 \mid \leq 910.1$ & $r \ldots$ \\
\hline$\Lambda, 9$ & ror $1 \leq \varepsilon \cdot, q$ & YY.10.1 & $r M .0 \leq Y \Delta, \Lambda$ & $r \ldots 1$ \\
\hline $1 \Lambda, r$ & $P 199 \cdot V q, V$ & 8.1701 .7 & IVAVEY0.1 & $r \ldots r$ \\
\hline $1 r, 9$ & $r \wedge \odot \vee \wedge \cdot \vee, \cdot$ & $P \vee \cdots \wedge \wedge, q$ & $r \leq \wedge \vee \vee \backslash \wedge .1$ & $r \cdot . \varepsilon$ \\
\hline$\varepsilon, r$ & $1 \cdot 1 \wedge r \mu \wedge r, r$ & $\varepsilon r \wedge \wedge \wedge \theta, 1$ & $q V \leq r \leq V V, 1$ & $r \ldots o$ \\
\hline
\end{tabular}

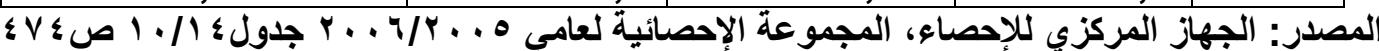

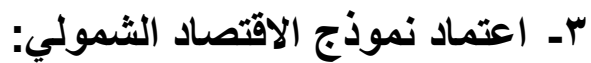

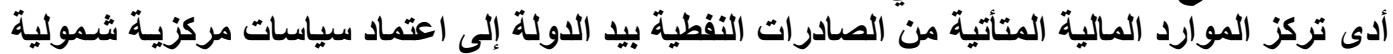

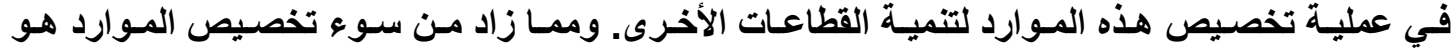

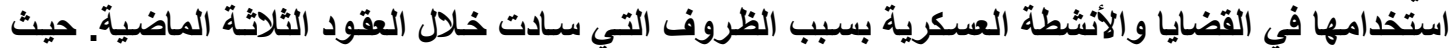

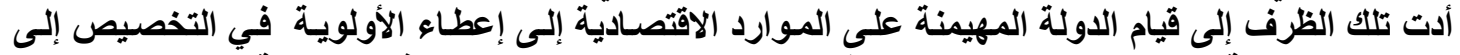

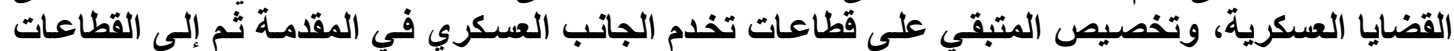

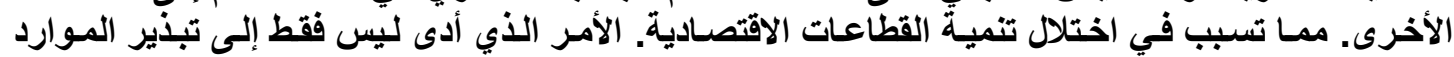

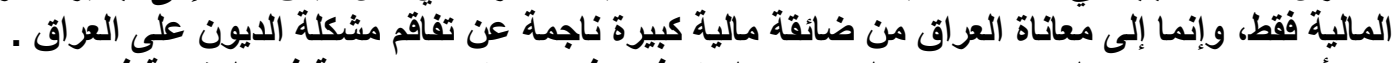

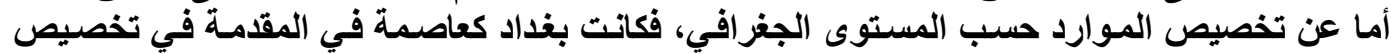

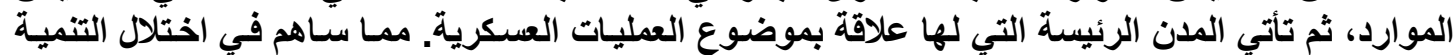
على مستوى مناطق العراق ولم تتمكن الخطط الموضوعة من تحقيق التهائ التنمية في المناطق بشكل منوازن. ع - ضعف القطاع الخاص القئ

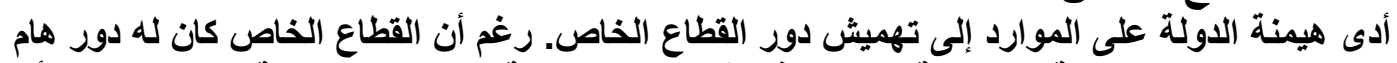

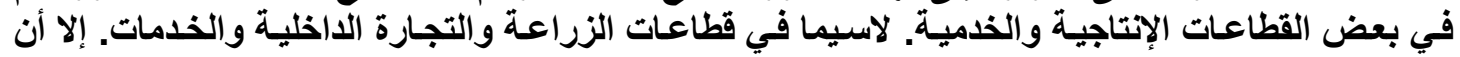

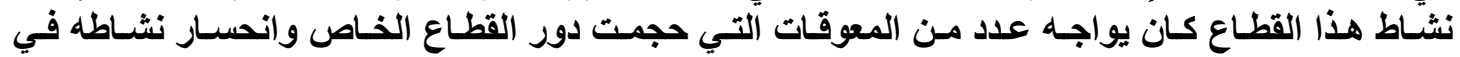

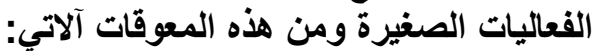

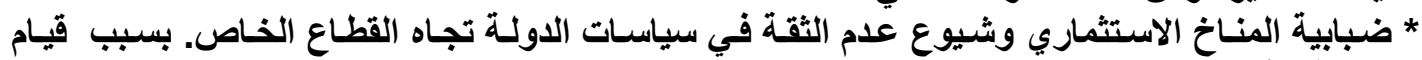

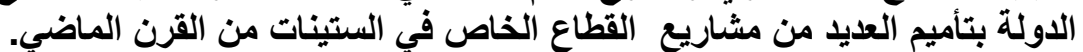

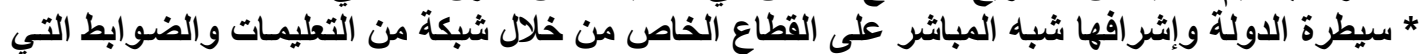
كاتت تضعها الدولة تجاه القطاع الثيط الخاص.

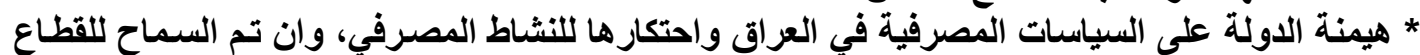

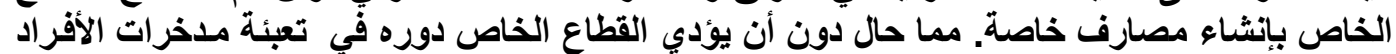
بغية استثمارها في مشروعات استثمارية كبيرة.

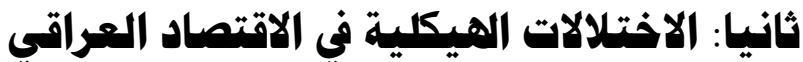

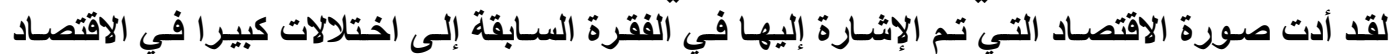

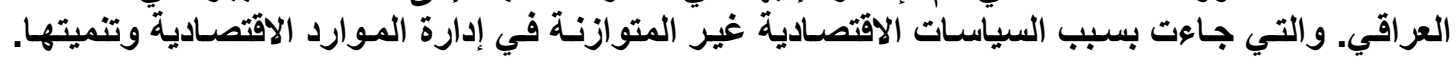
ويمكن إيجاز أهم هذه الاختلالات بالنقاط آلاتية:

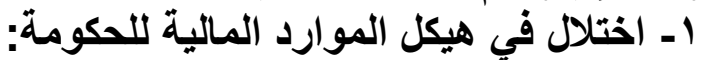

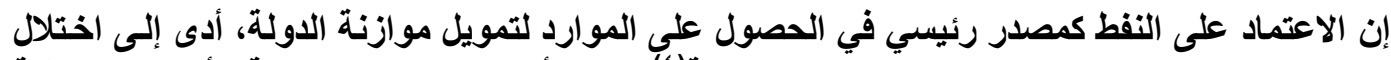

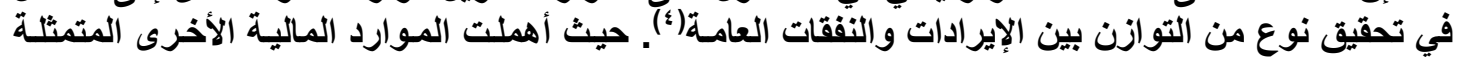

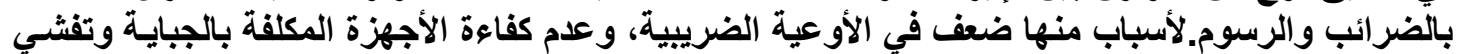

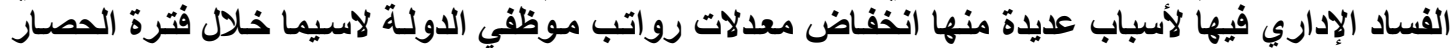

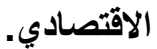

r - درجة عالية من الاعتماد على الخارج

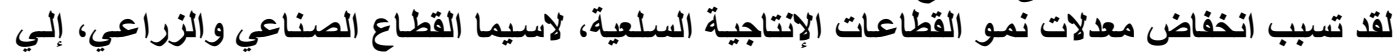

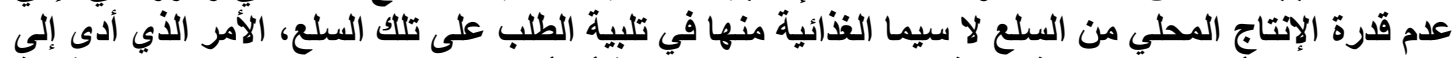

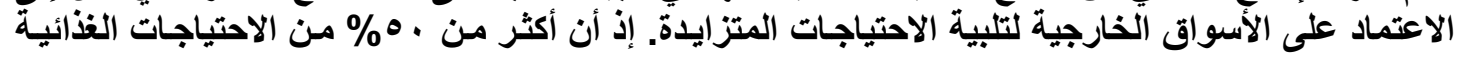




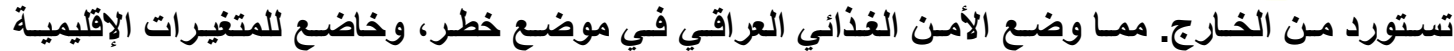

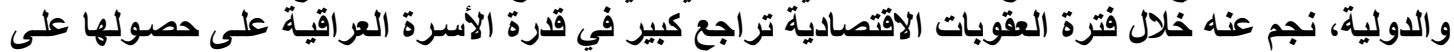

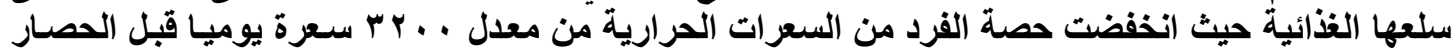

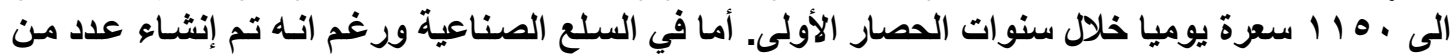

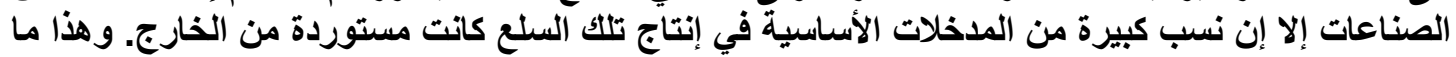

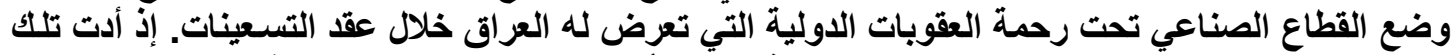

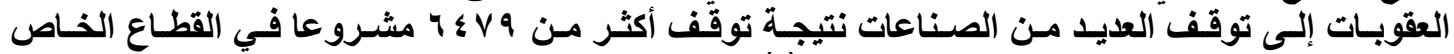

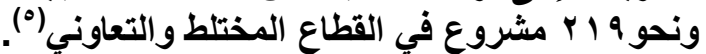

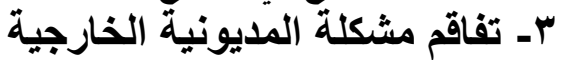

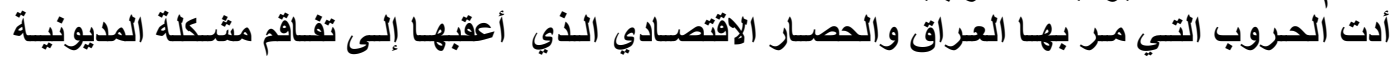

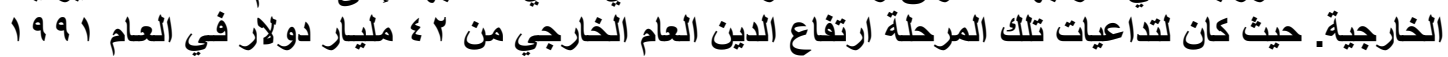

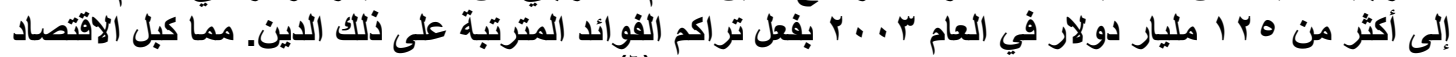

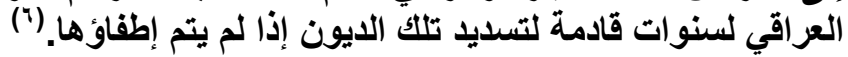

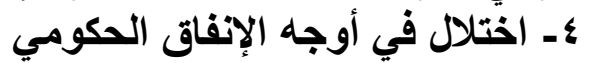

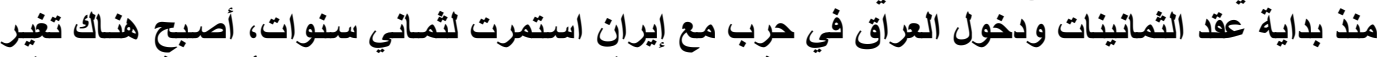

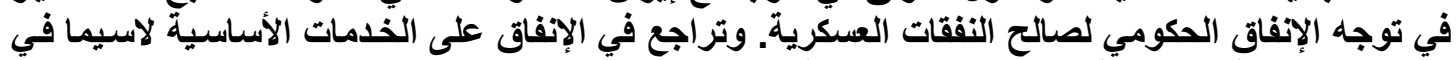

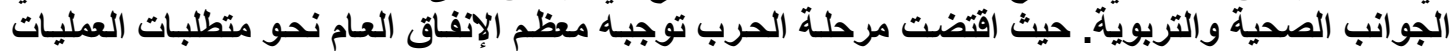
العسكرية.

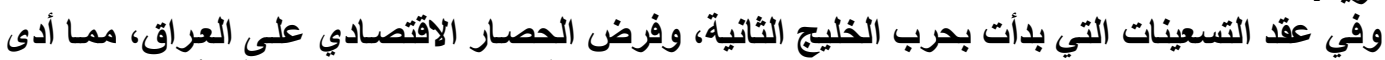

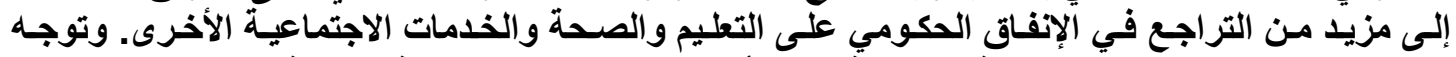

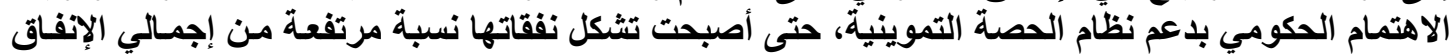

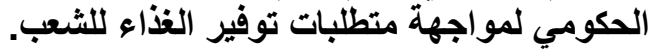

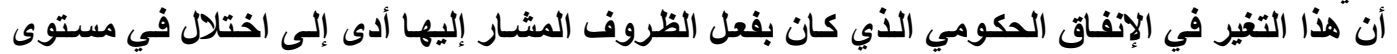

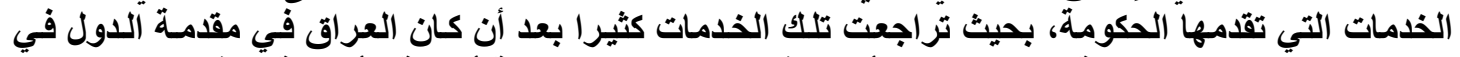

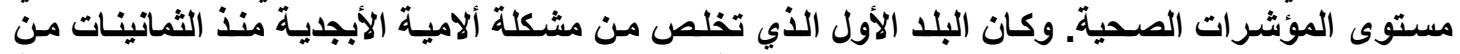

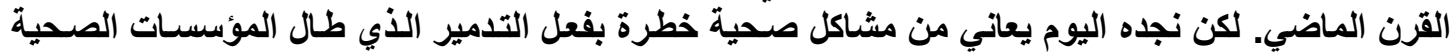

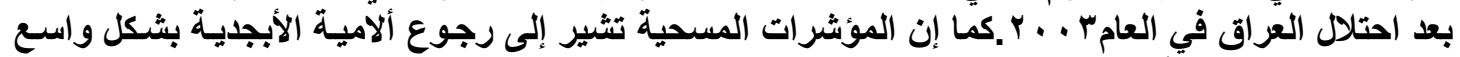
لاسيما بين صفوف الأطفال .

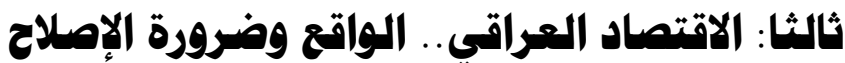

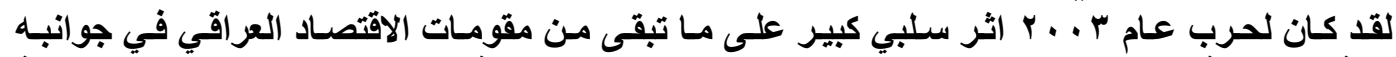

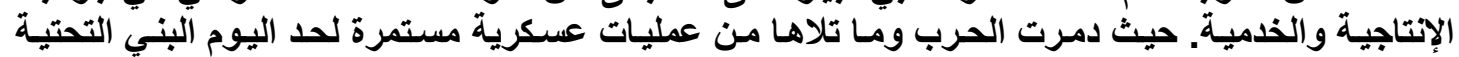

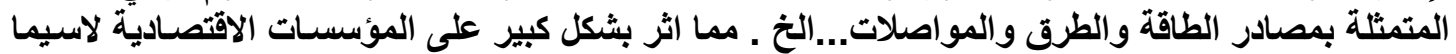

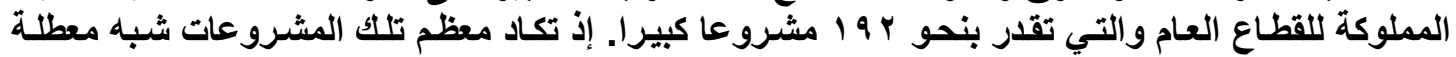
بسب نقص الطاقة ومستلزماتُ العام العملية الإنتاجية.

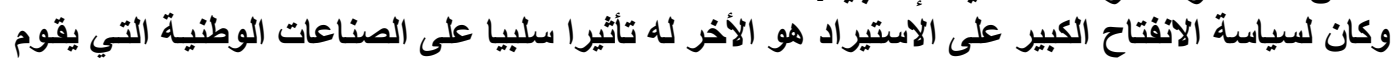

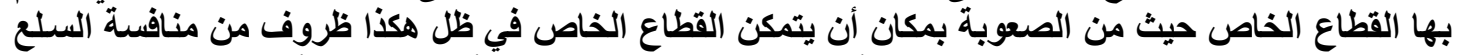

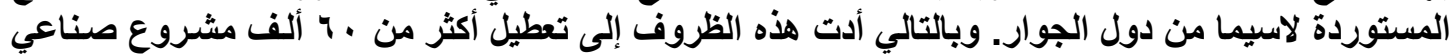

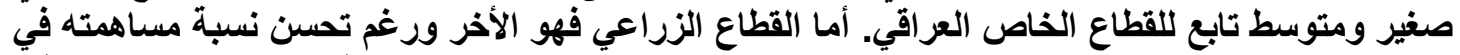

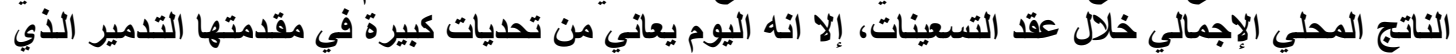

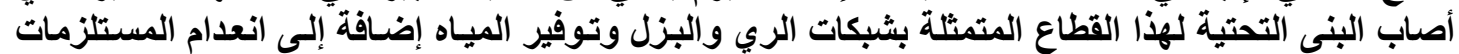

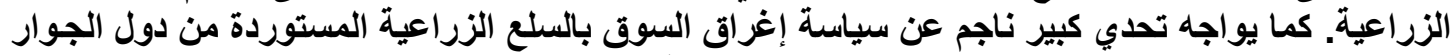

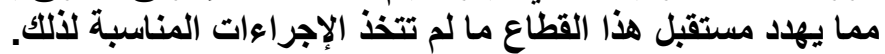

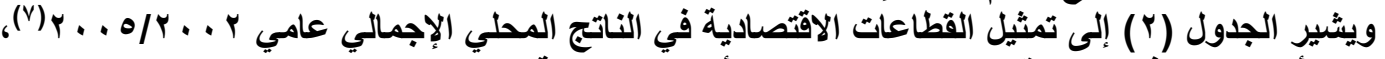

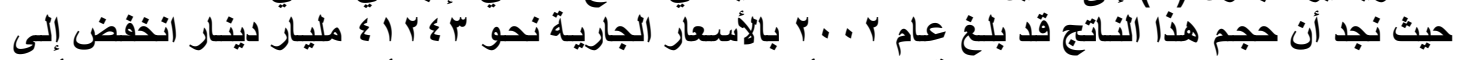
؟

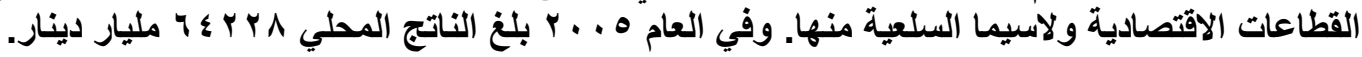

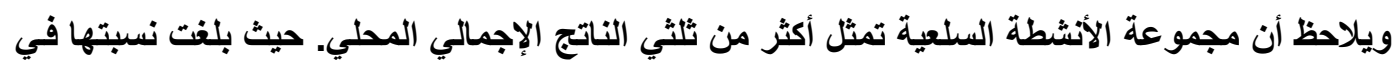

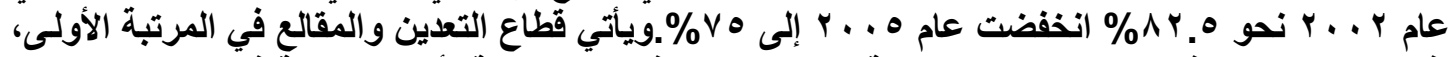

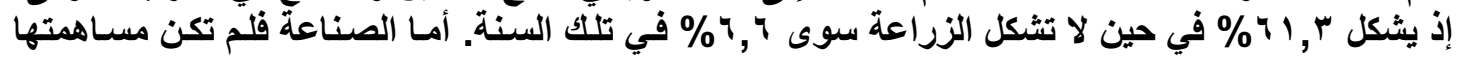


سوى 9, 1\% مما يؤشر الظلل الكبير في أداء هذا القطاع رغم كونـه يمثل النثـاط الذي يعتمد عليه شريحة

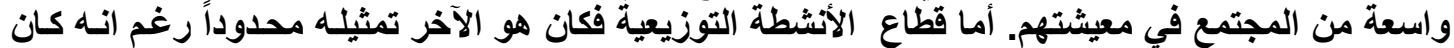

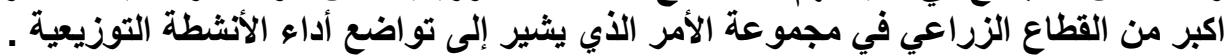

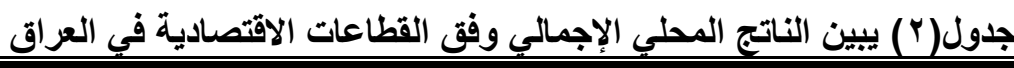

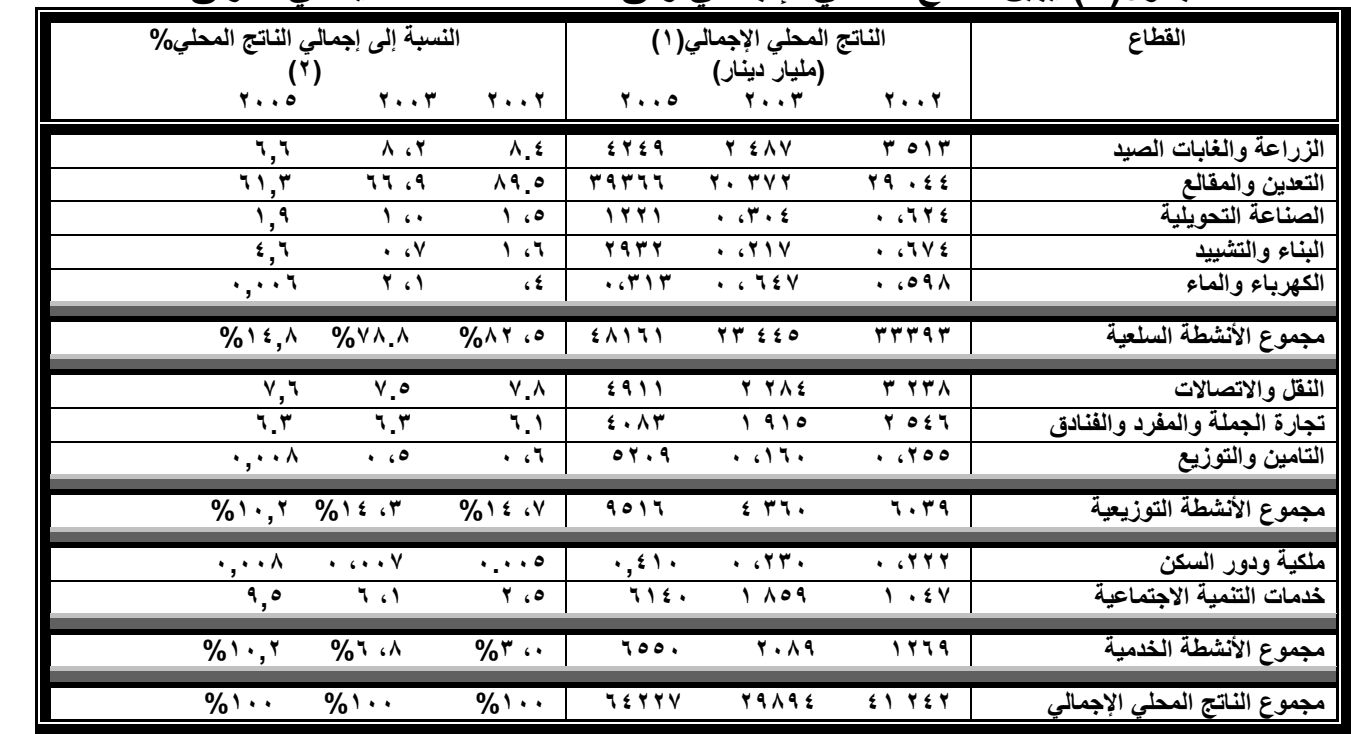

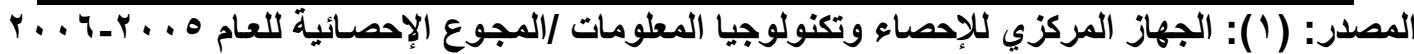

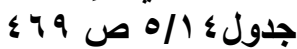

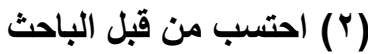

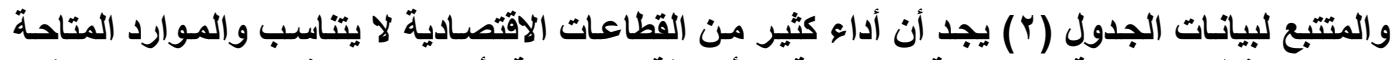

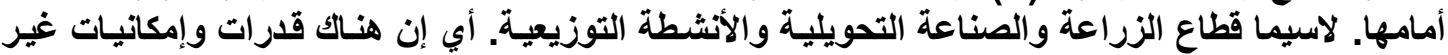

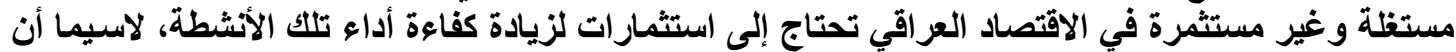

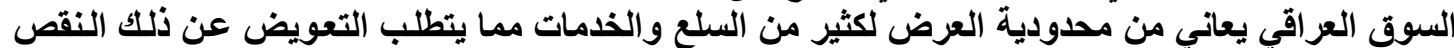
بالاستيراد من الخارج رغم توفر الإمكانيات لإنتاجها في الداخل.

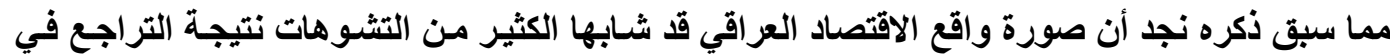

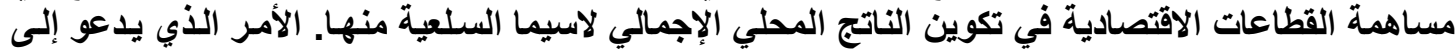

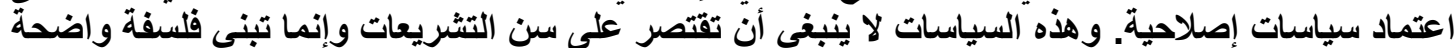

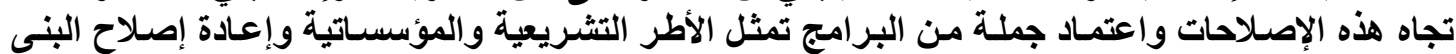

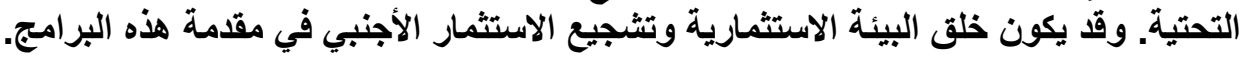




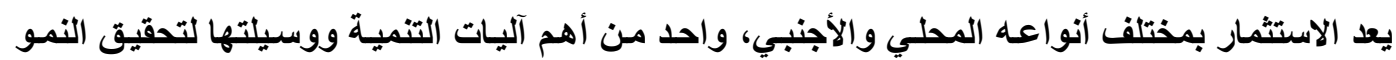

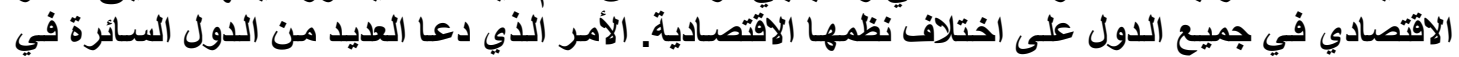

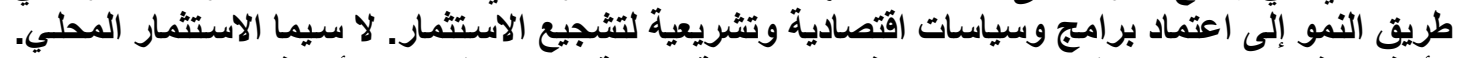

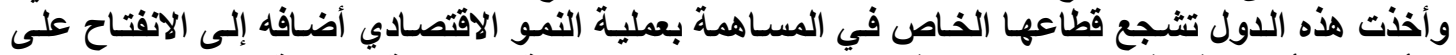

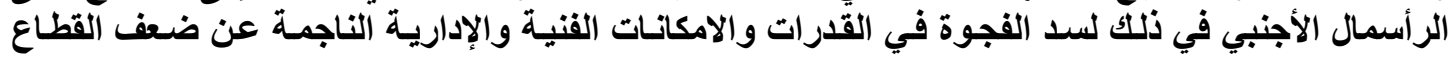

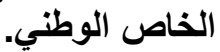

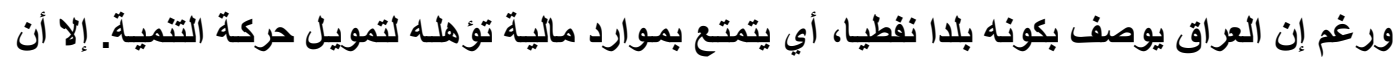

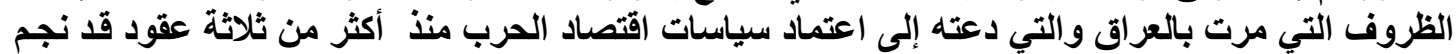

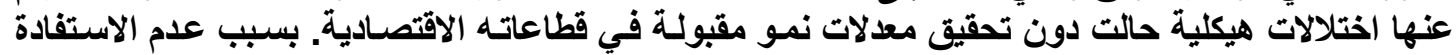

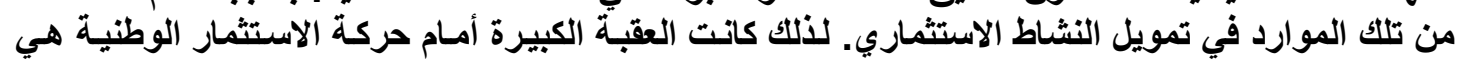

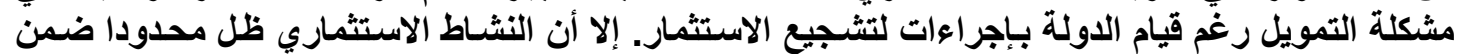

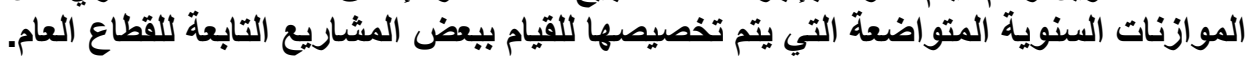

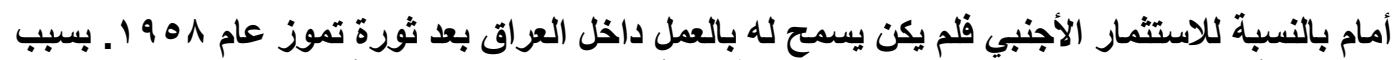

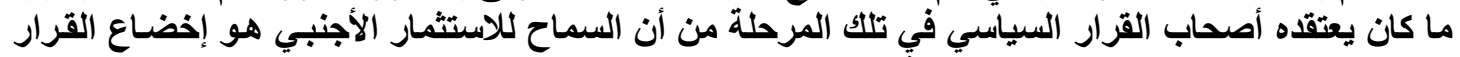

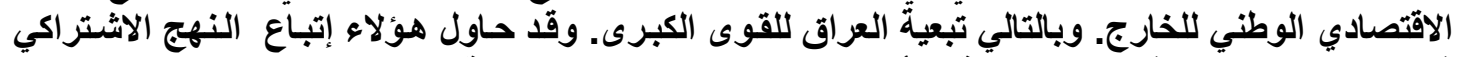

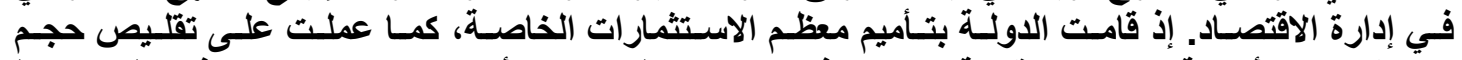

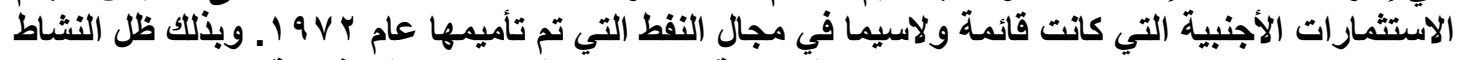

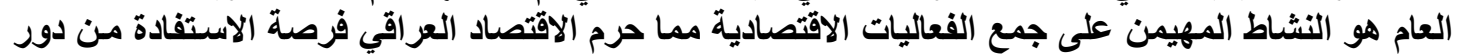

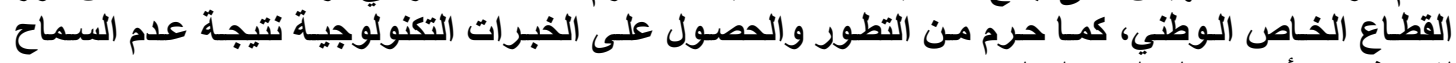
للاستثمار الأجنبي بالعملّ داخل العراق.

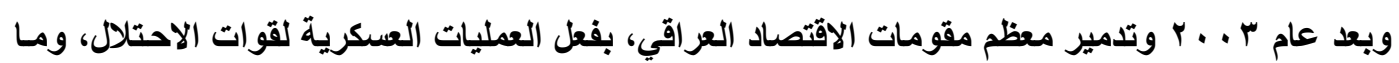

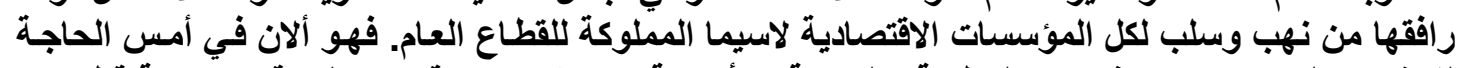

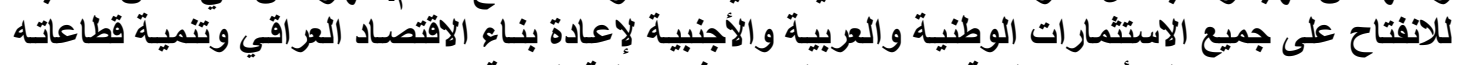

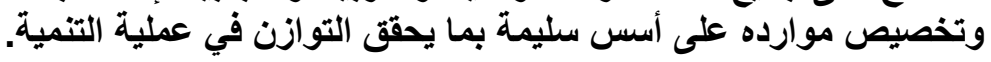

(ب) معوقات النشاط الاستثماري

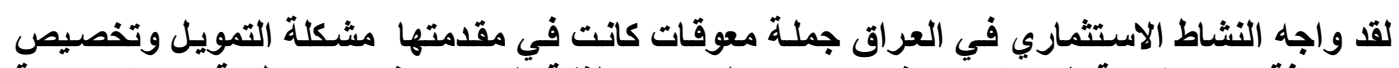

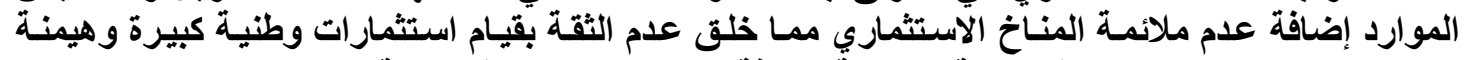

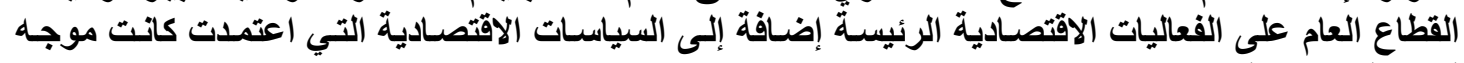

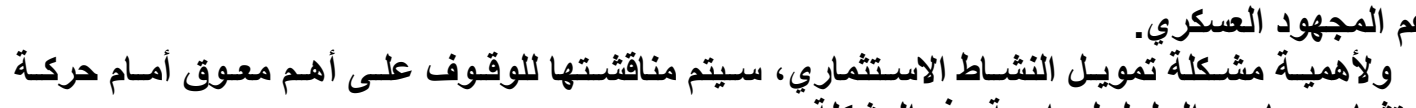

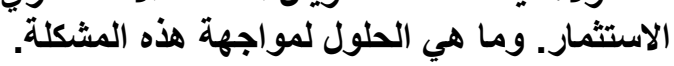
(ج) تمويل الاستثثمار

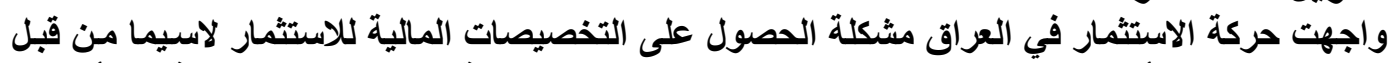

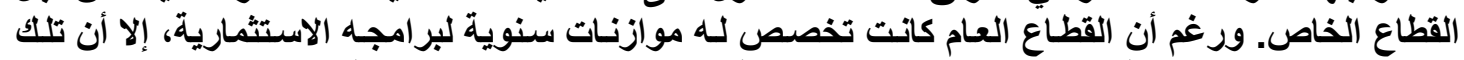

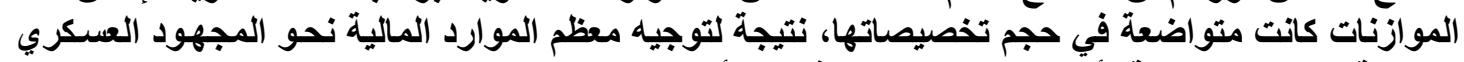

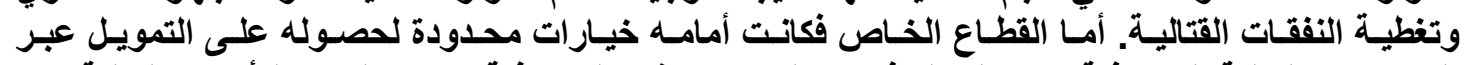

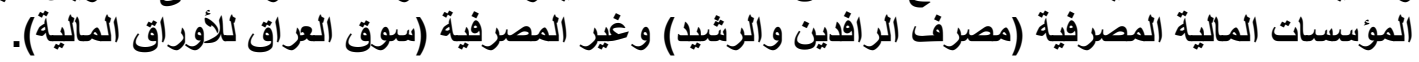




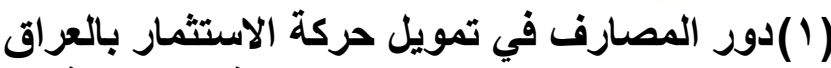

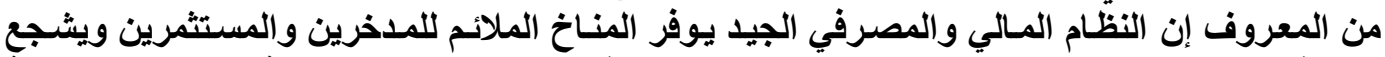

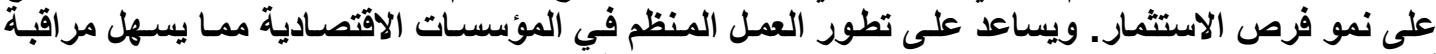

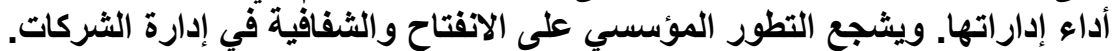

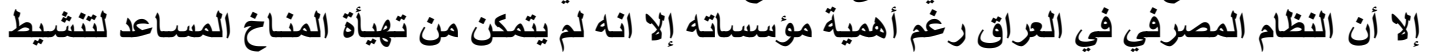

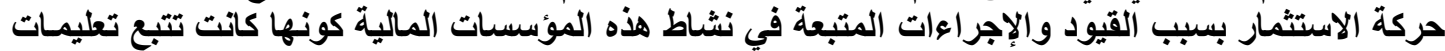

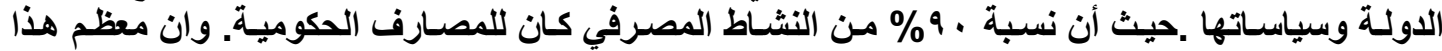

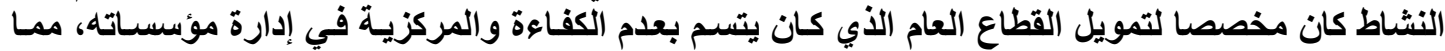

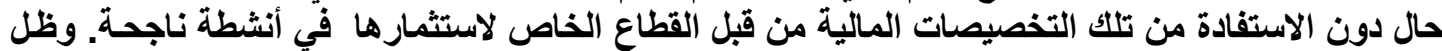

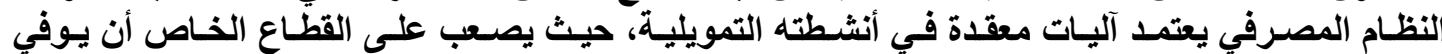

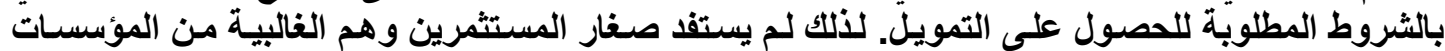

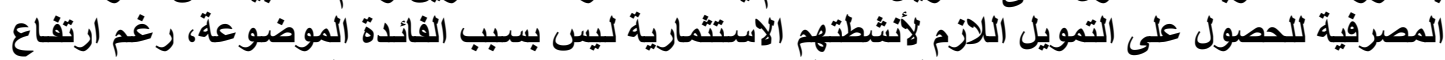

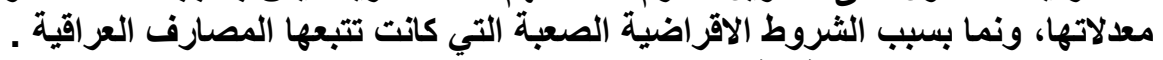

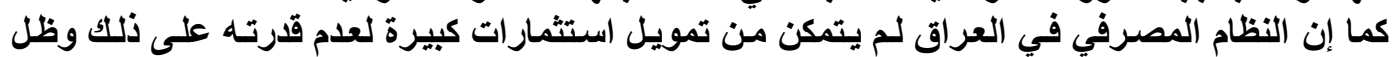

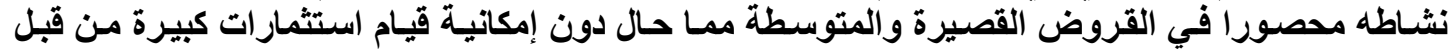

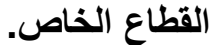

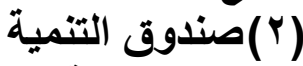
حاولت الدولة تثجيع حركة الاستثمار في العراق بعد تراجع معدلات النمات النمو في القطاعات الاقتصسادية

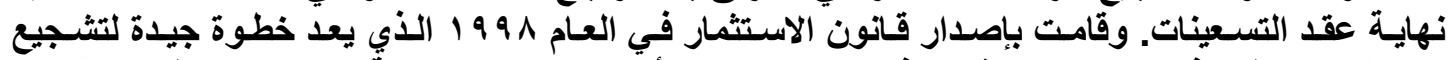

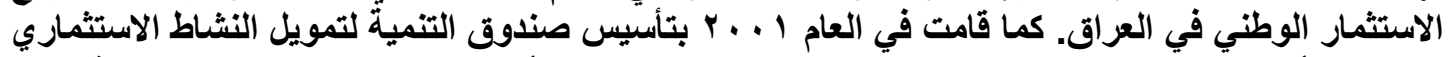

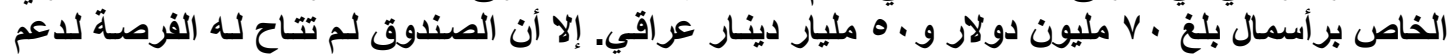

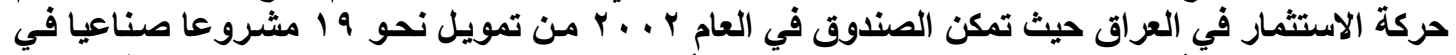

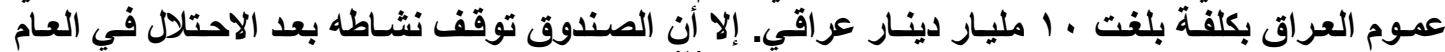

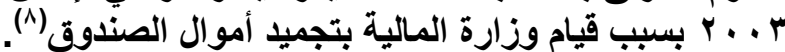

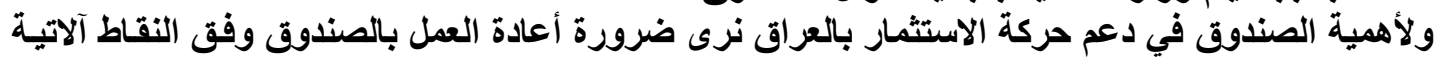

• إثرادة ممثلين عن القطاع الخاص في إدارة الصندوق ومن ذوي الخبرة

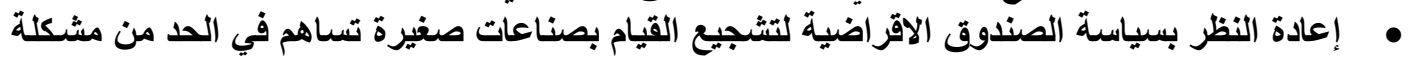

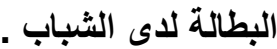

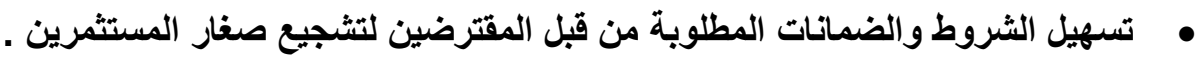

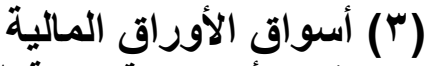

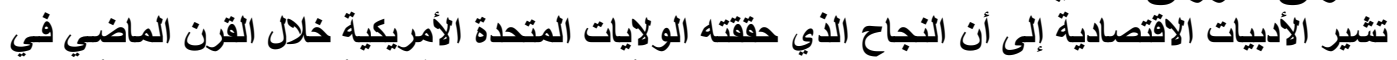

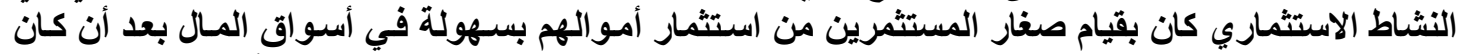

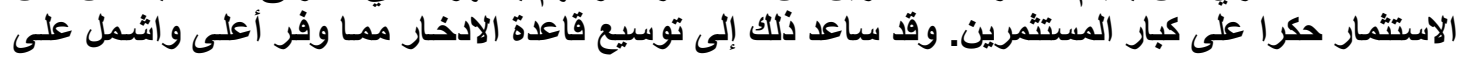

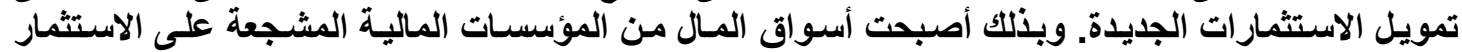

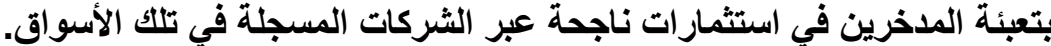

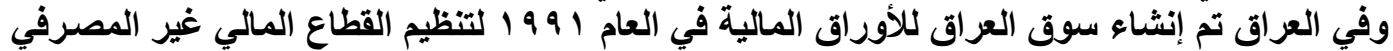

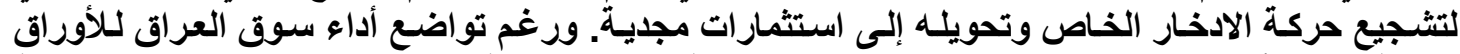

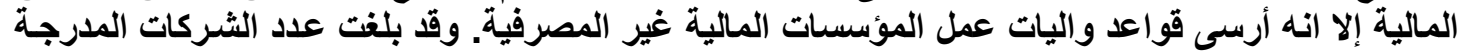

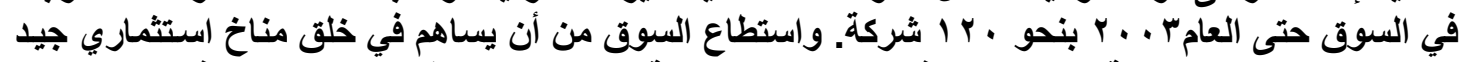

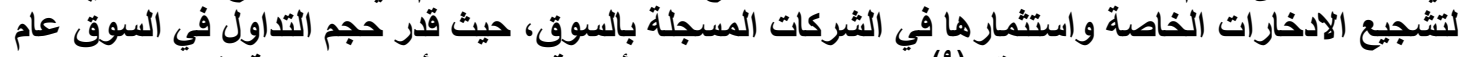

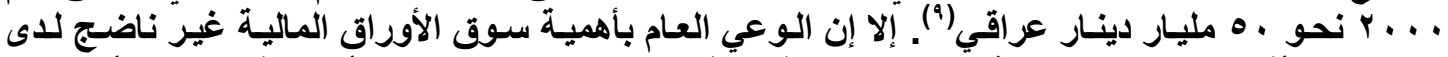

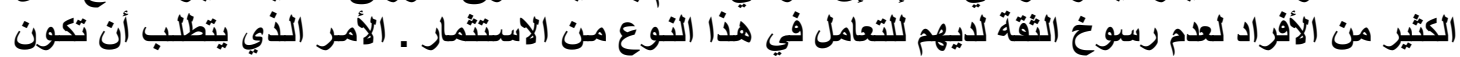

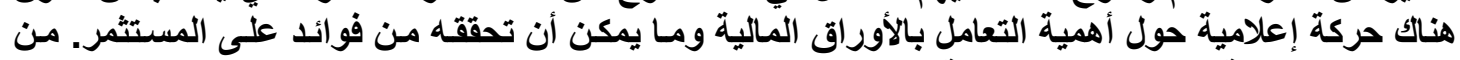
اجل تثجيع حركة الاستثمارات الوطنية. 


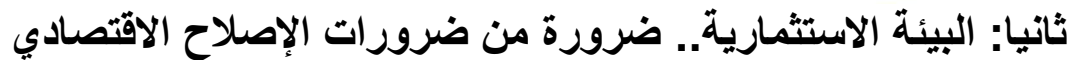

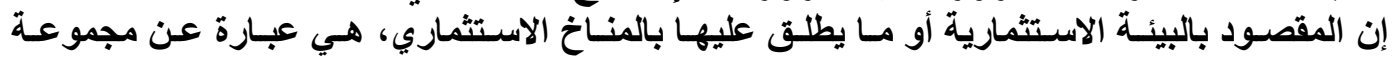

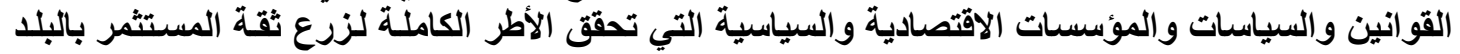

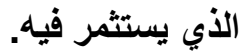

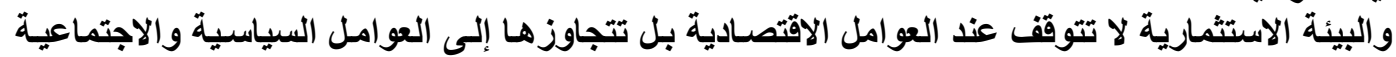

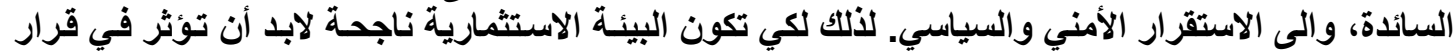

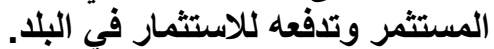

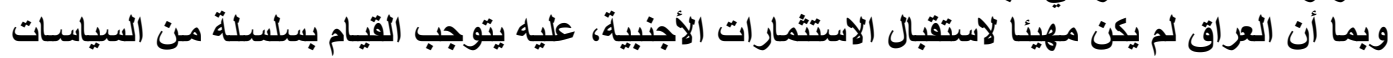

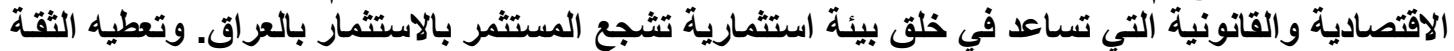

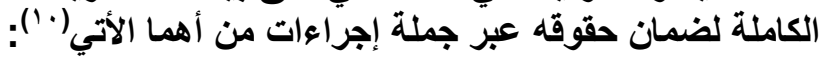

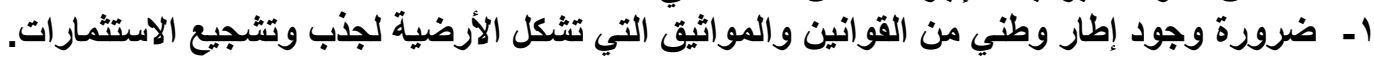

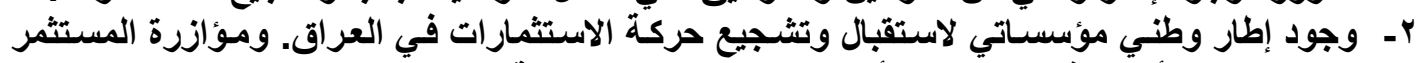

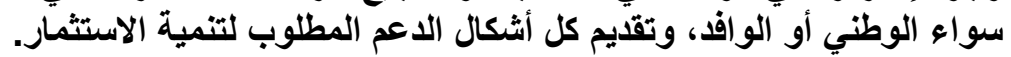

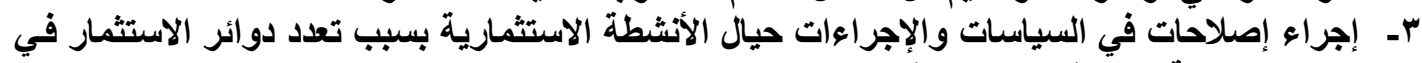

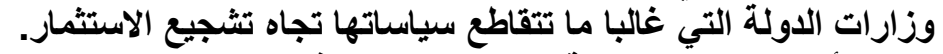

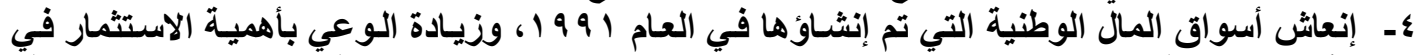

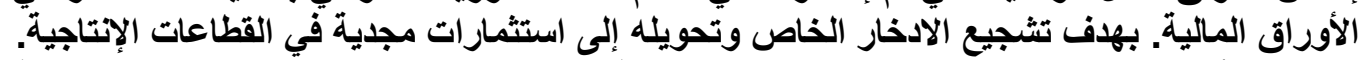

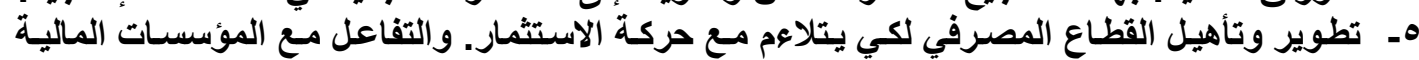

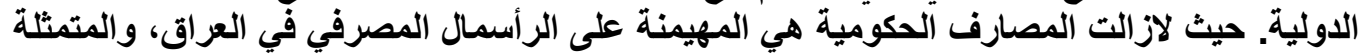

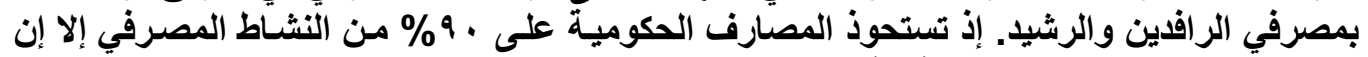

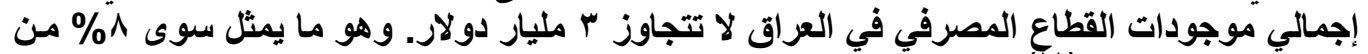

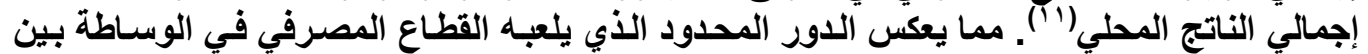

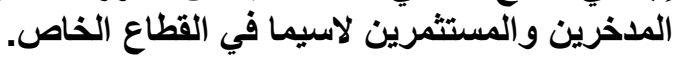

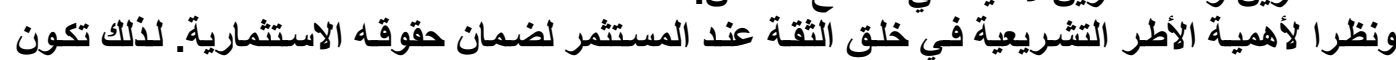

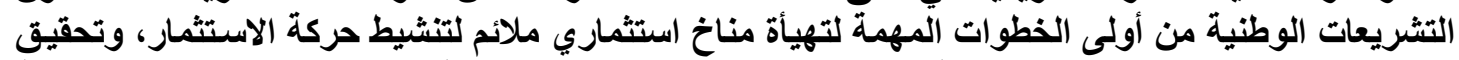

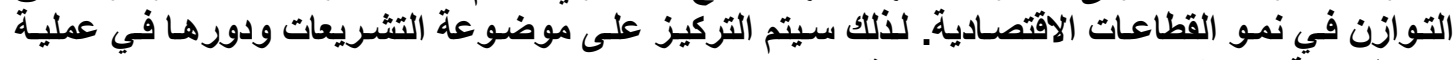

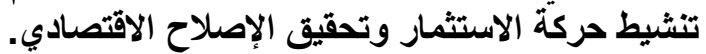

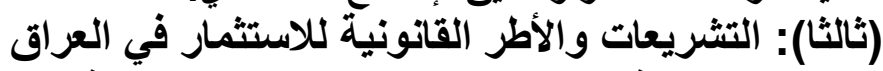

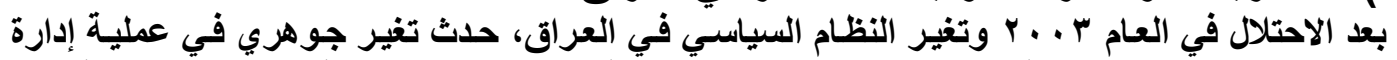

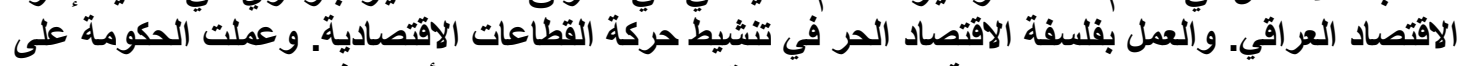

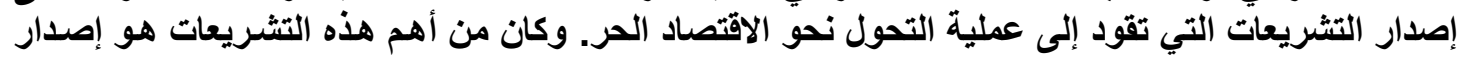

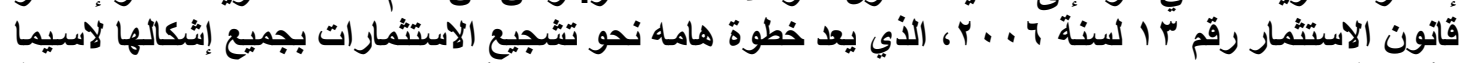

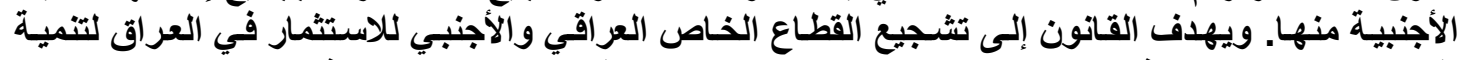

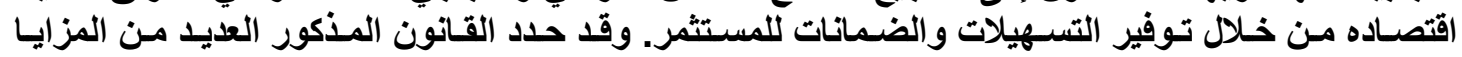

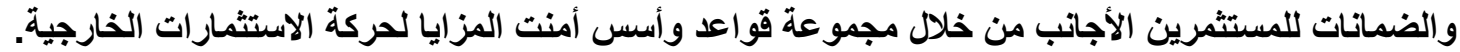

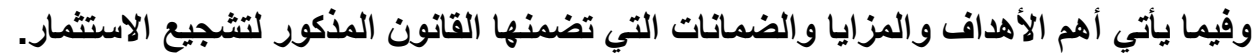

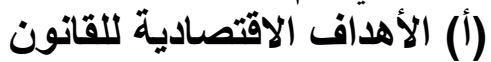

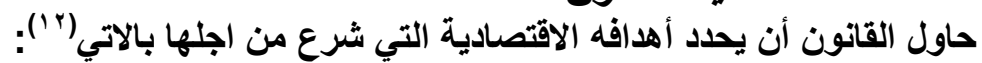
• •

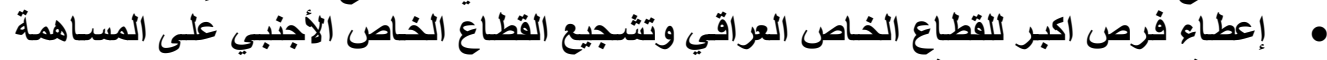
بتنمية الموارد الاقتصادية.

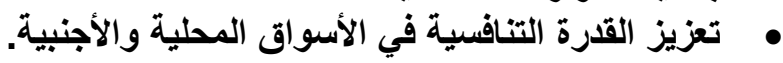

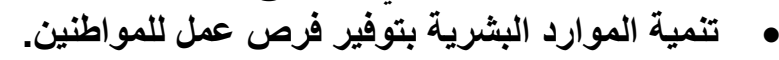
• توسيع الصادرات وتعزيز ميزان المدفوعات فئرئ العراقي والميزان التجاري. 


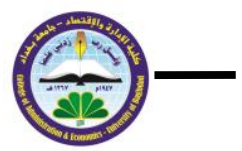

(ب) مجالات الاستثمار

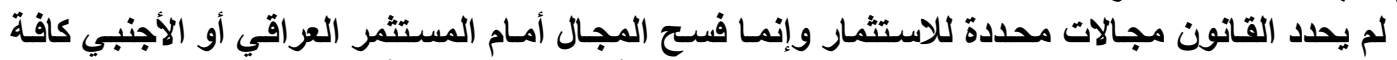

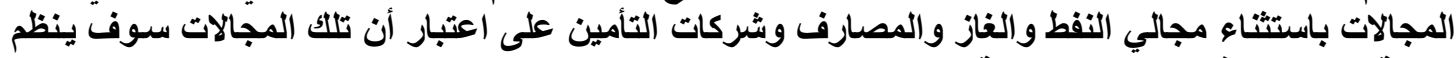

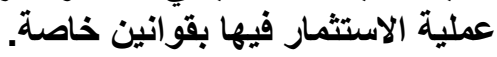

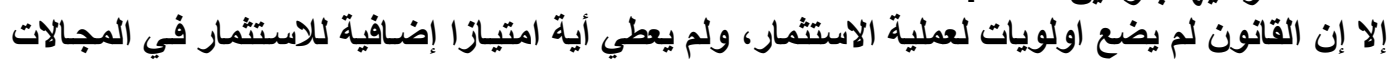

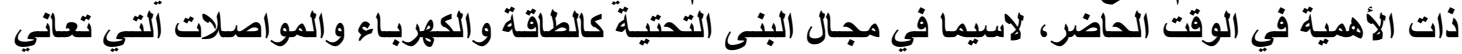
من تدهور كبير في أنشطتها.

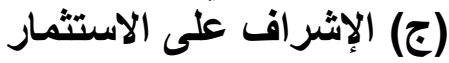

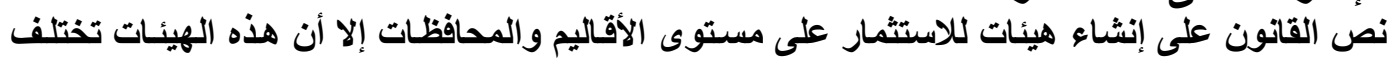

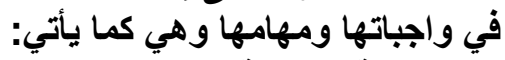

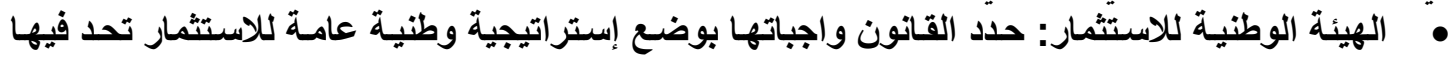

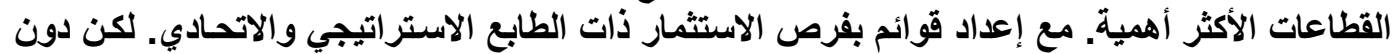
أي إلزام في تنفيذها أو إعطاء أية حوافز أفز للاستثمار فيها.

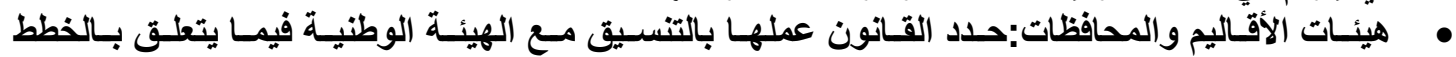

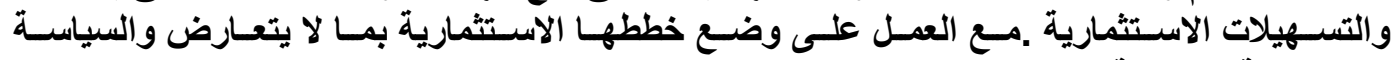
الاستثمارية الاتحادية الاستية

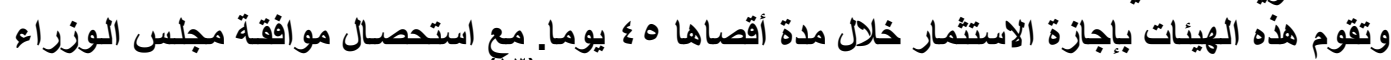

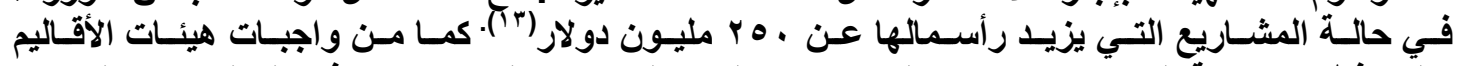

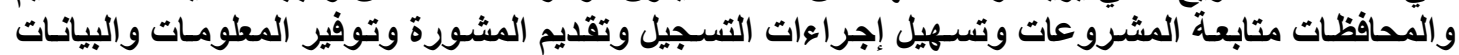
ل المستثمرين.

(د) التسريلات والامتيازات الممنوحة للمستثمرين

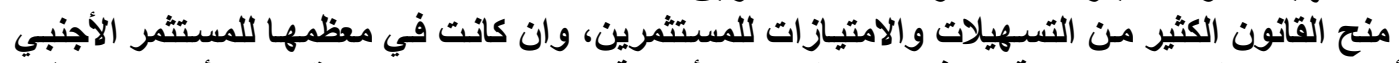

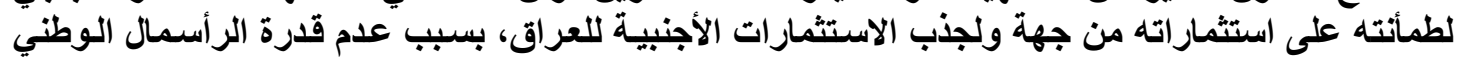

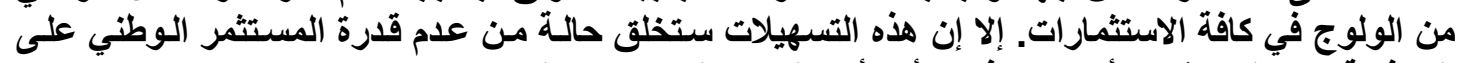

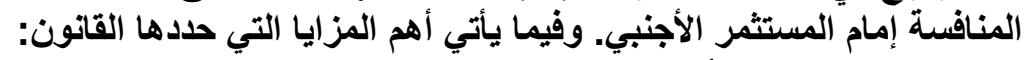

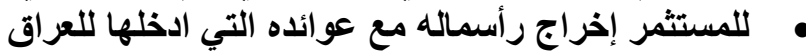

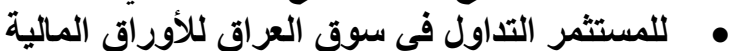

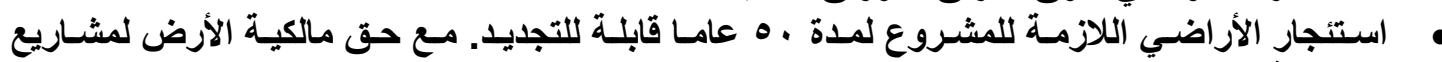
الإسكانية. • عدم مصادرة أو تأميم المشروع الاستثماري.

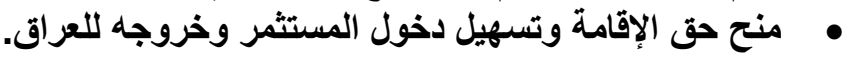

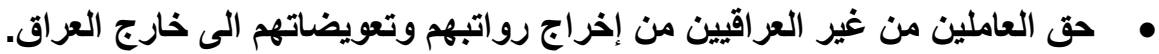

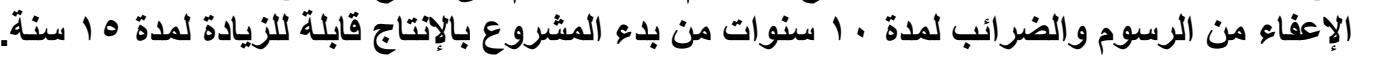

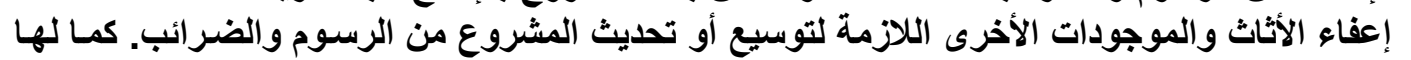

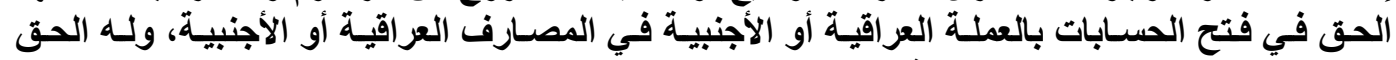
بالتامين لَّى شركات التامين الوطنية.

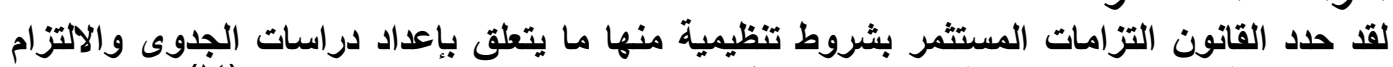

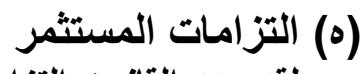

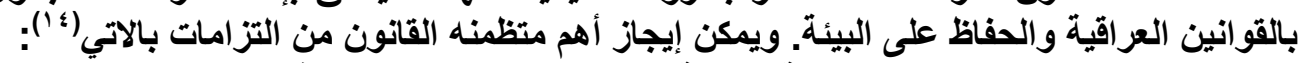

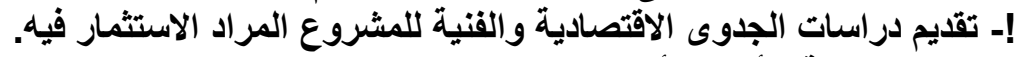

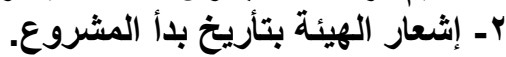

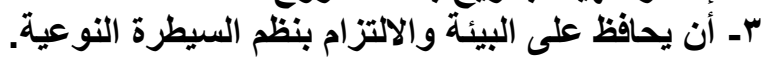

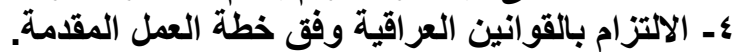
هـ مسك سجل المواد المستوردة مع مسك حسابات أصنول أصولية يدققها محاسب مجاز. 


\section{رابعا: قانون الاستثمهار وعملية الإصلاح الاقتصادي}

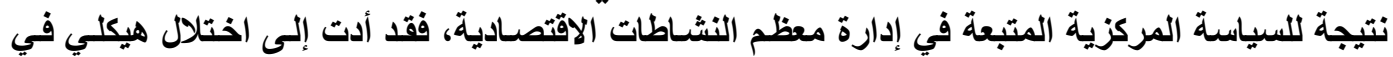

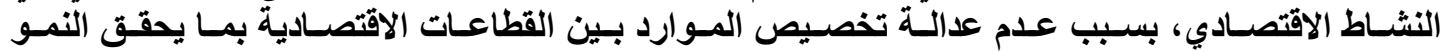

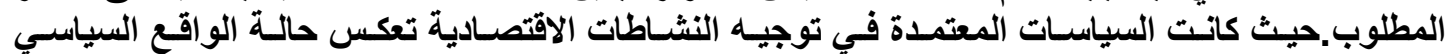

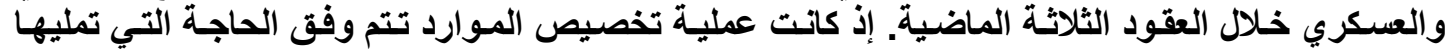

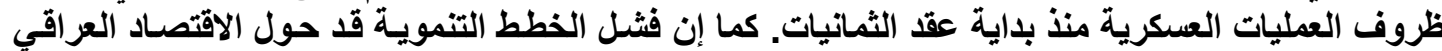

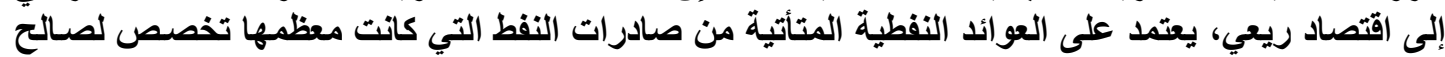
المجهود العسكري. وبالتالي أدى إلى حرمان القطاعات الاقتصادية من الموارد التي كـان بالامكان التهان أن تحقق التق النمو فيها.

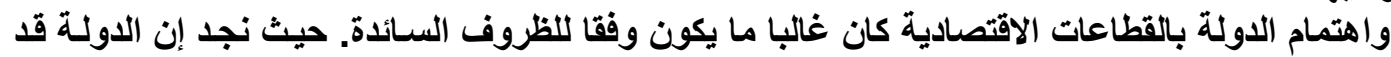

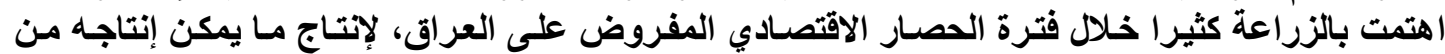

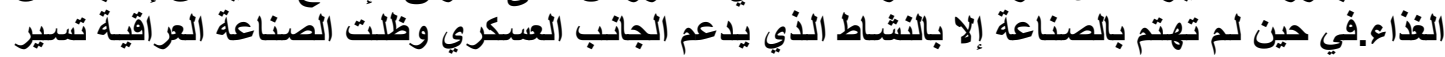

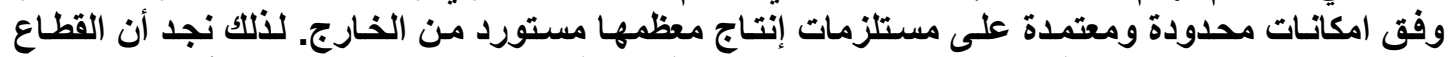

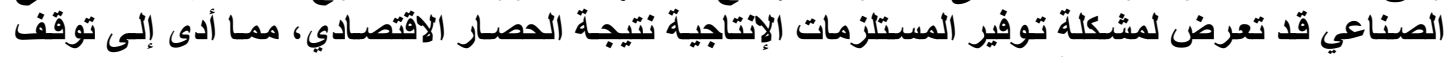

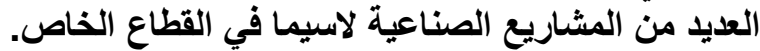

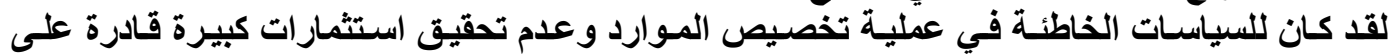

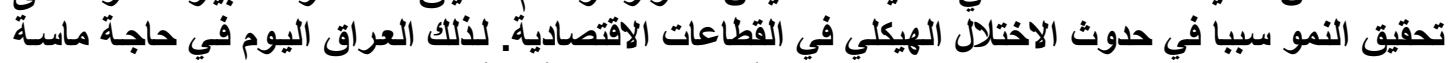

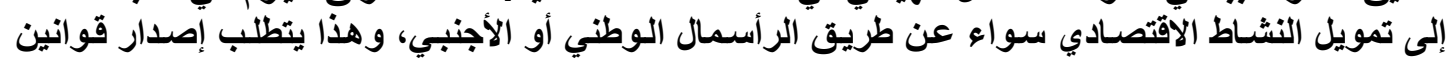

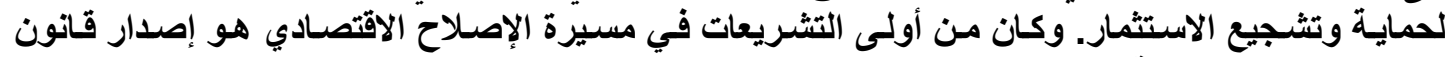

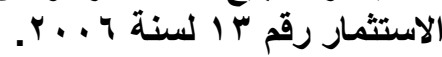

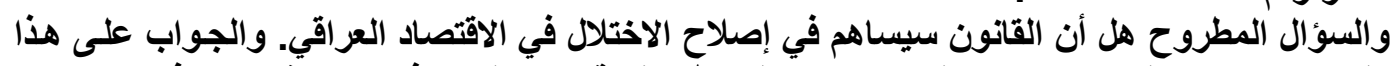

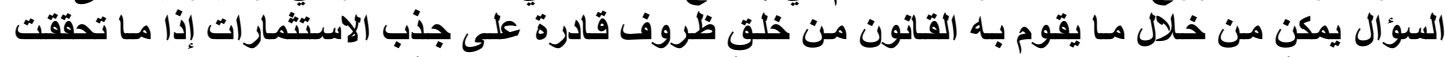

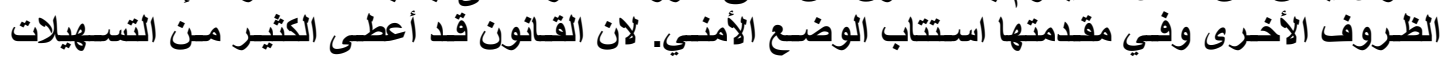

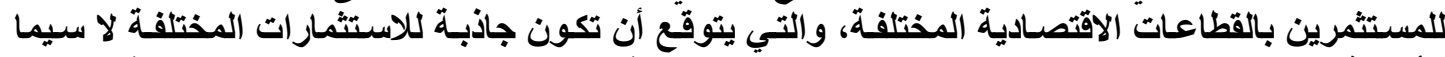

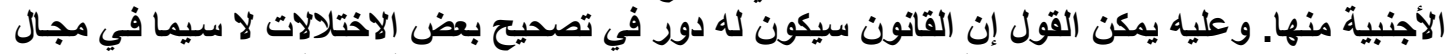

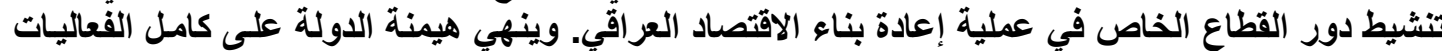

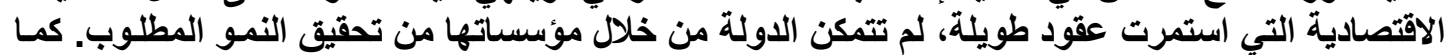

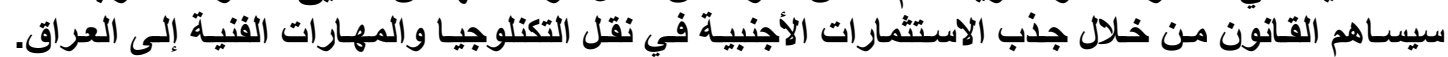

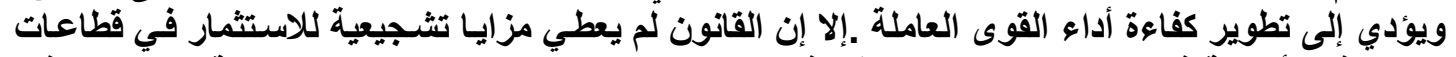

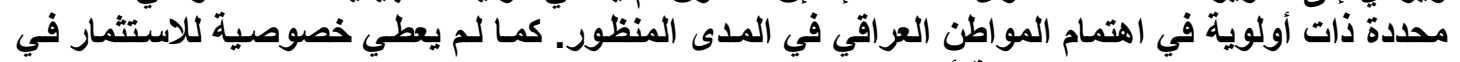

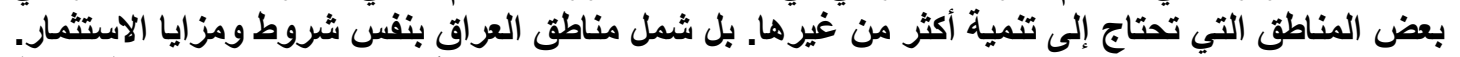

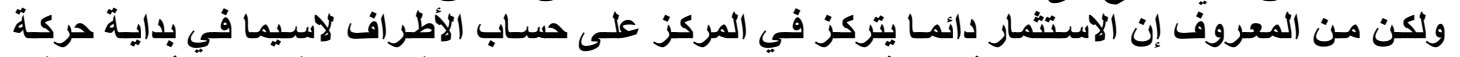

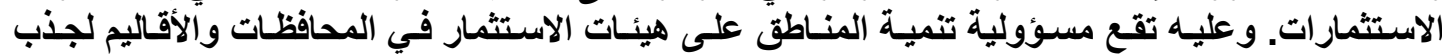

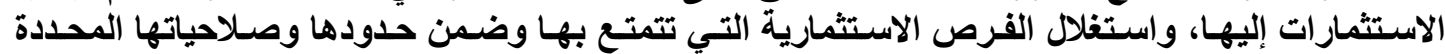

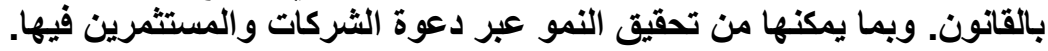




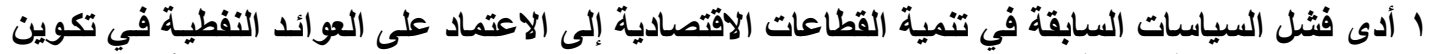

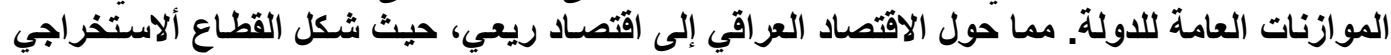

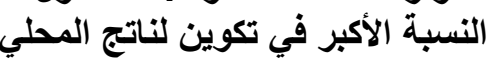

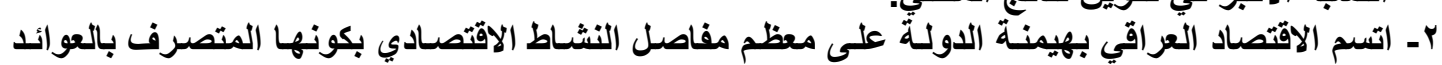

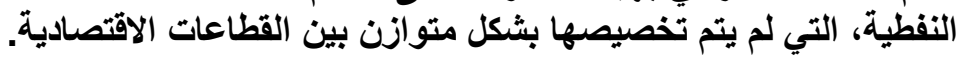

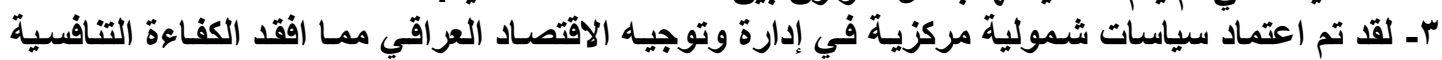

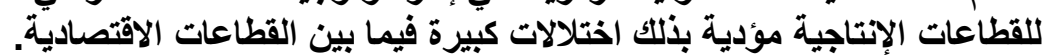

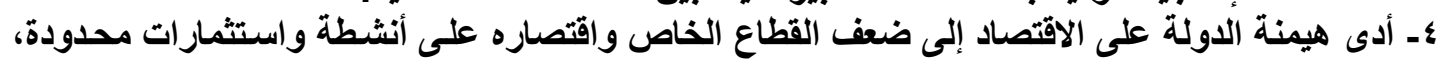

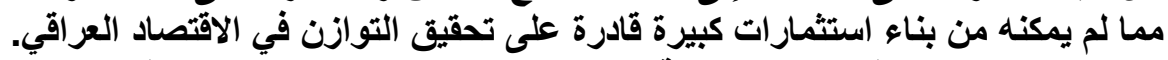

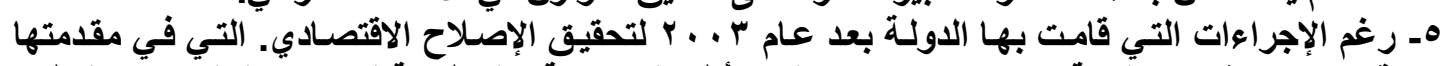

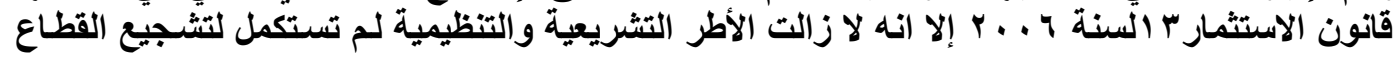

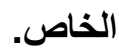

اـ تبني فللفة واضحة في إدارة الاقتصاد العراقي وفق آلية السوق، ويمشاركة الدولة في توجيه ودعم

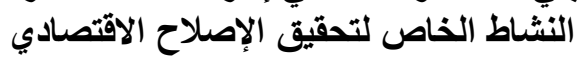
r- ضرورة وجود إطار وطني من القوانين والَمواثيق التي تثكل الأرضية لجذب وتثبيع الاستثمارات المحلية والأجنبية.

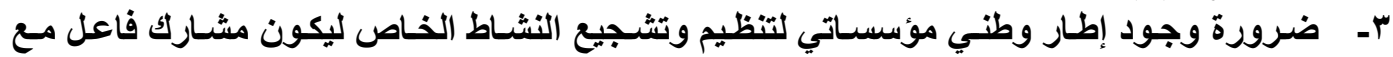

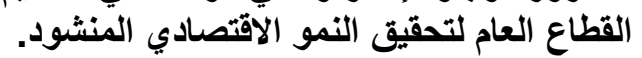

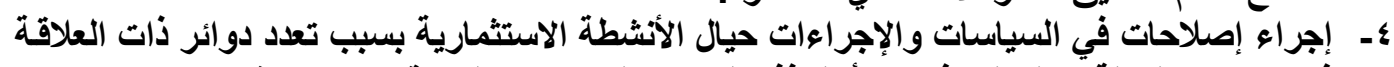

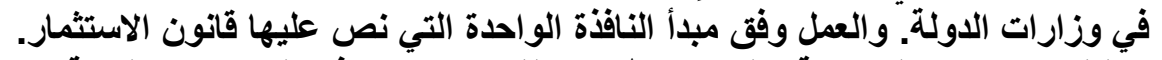

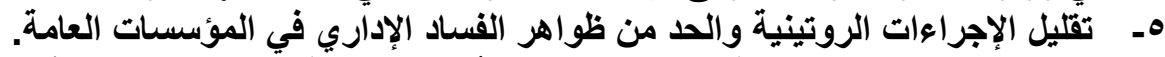

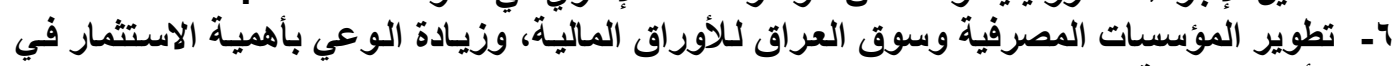

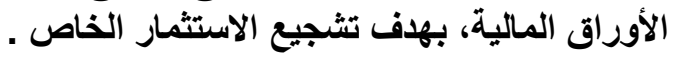




\section{المادر والهواهش}

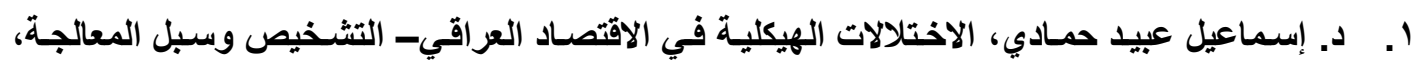

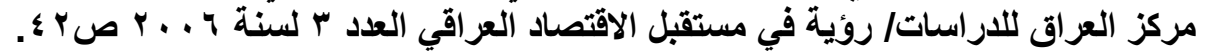

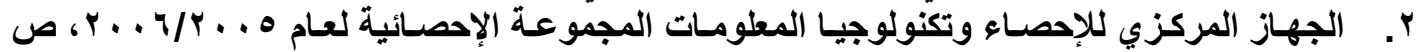
. 807

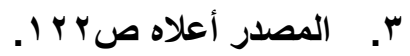

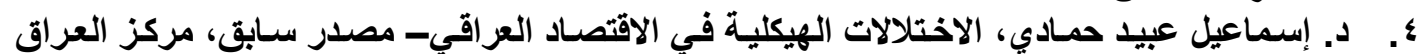

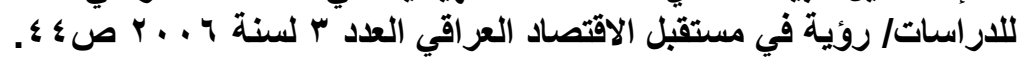

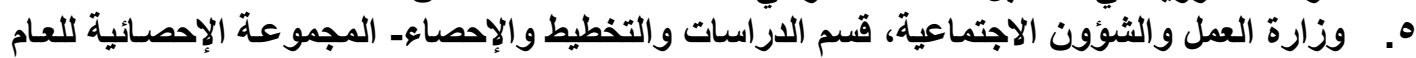
.1999

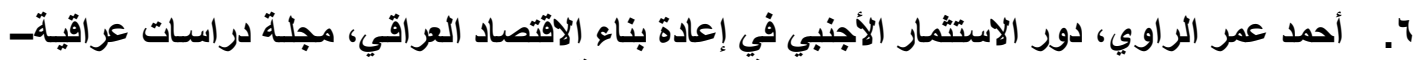

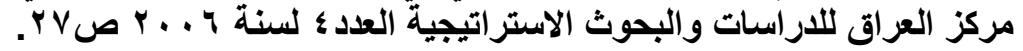

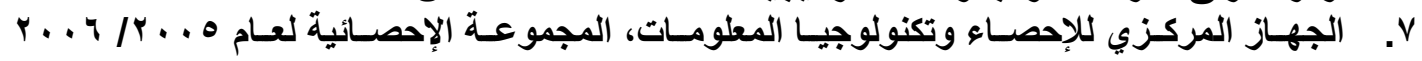

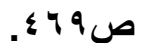

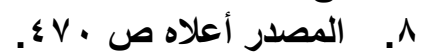

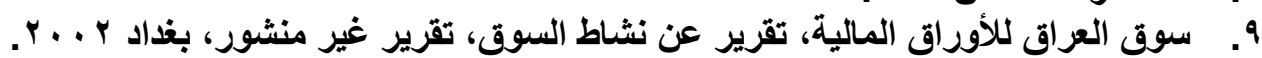

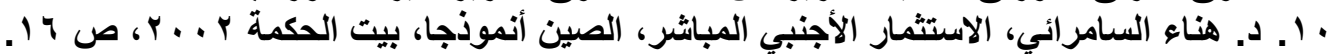

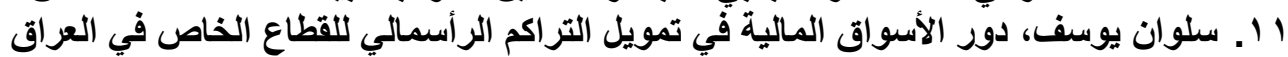

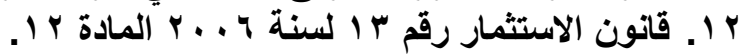

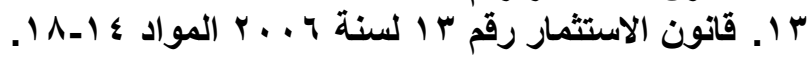

